Check for updates

Cite this: RSC Adv., 2021, 11, 6682

Received 18th December 2020 Accepted 29th January 2021

DOI: 10.1039/d0ra10629a

rsc.li/rsc-advances

\section{Synthetic strategies for aryl/heterocyclic selenides and tellurides under transition-metal-catalyst free conditions}

\begin{abstract}
Debasish Kundu (DD *
Aryl and heteroaryl selenides and tellurides are found to have broad applications in the diverse fields such as medicine, biology, materials science, pharmaceutical etc. and thus their synthesis remains a challenging field for synthetic chemists in last decade. Although a large no of methodologies have been developed based on metal catalyzed $\mathrm{C}$-Se/Te coupling, a large number of researches has been focused on developing metal catalyst free protocols due to their sustainability in recent times. This review covers all the recent developments in last decade on their synthesis under metal catalyst free conditions by using different sustainable techniques e.g. greener reagents and solvents, ball milling, visible light photocatalysis, microwave, ultrasound etc.
\end{abstract}

\section{Introduction}

$\mathrm{C}-\mathrm{Se} / \mathrm{C}-\mathrm{Te}$ bond formations for the synthesis of organoselenides and tellurides are getting much attention from

Department of Chemistry, Government General Degree College at Mangalkote (Affiliated to The University of Burdwan), Khudrun, Purba Bardhaman, 713143, India. E-mail: chem.debasishkundu@mangalkotegovtcollege.org; debiitkgp123@ gmail.com

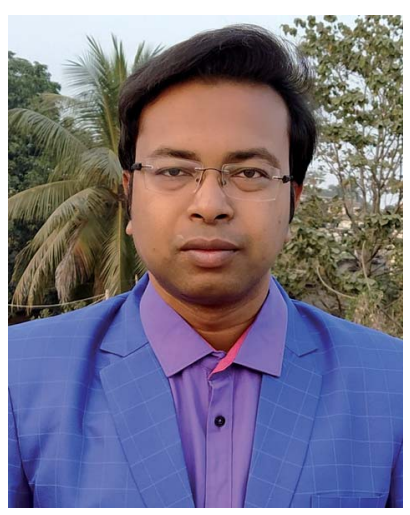

Dr Debasish Kundu was born in West Bengal, India and has done his B.Sc. from Visva-Bharati University (University Rank 1) and M.Sc. from IIT Kharagpur (University Rank 1). Dr Kundu has completed his Ph.D. from IACS-Kolkata and received Elli Lilly Asia Outstanding Thesis Award in 2015. Currently he is assistant professor in Government General Degree College at Mangalkote and his research interest is focused on transition metal catalyzed cross coupling and $\mathrm{C}-\mathrm{H}$ activation. He has published the pioneering research in the field of $\mathrm{Ni}$ and $\mathrm{Co}$ catalyzed $\mathrm{C}-\mathrm{O}$ cross coupling. He was the recipient of Marie Skłodowska-Curie Seal of Excellence Award from European council in 2017. He was the visiting scientist in $65^{\text {th }}$ Lindau Nobel Laureate Meeting in Germany and also visited several research institutes in Germany, France, Austria and Switzerland. Dr Kundu has published more than 30 articles in several prestigious national and international journals of ACS, RSC, Wiley, Elsevier. organic chemists due to their important applications in biological, environmental and pharmaceutical fields of study. ${ }^{1}$ They also have great significance in structural chemistry, ${ }^{2}$ materials science ${ }^{3}$ and in synthetic chemistry acting as reagents in broad array of synthesis and catalysis. ${ }^{4}$ Se and Te based molecules were also found to have interesting applications in semiconductors, magnets and NLO materials. ${ }^{5}$ Furthermore the increasing interests in selenium and tellurium chemistry is coming from the recent developments of Se- and Te-based organocatalysts which were found effective in several functional group transformations under sustainable condition for the synthesis of bio-active molecules. ${ }^{6}$ Although organotellurides are less explored, organoselenides which are less toxic than selenium, were found to have diverse applications in medicinal and biological fields by showing anticancer, anti-HIV and anti-bacterial activities. ${ }^{7}$ Aryl and heteroaryl selenides are found to have large array of applications against several human diseases and thus been applied in human body as potential therapy against them (Fig. 1). ${ }^{\mathbf{8} 9}$ Among heteroaryl selenides $N$ based heteroaryl selenides such as selenylindoles, selenylimidazo[1,2- $a]$ pyridines were found most potential against human diseases due to the biological importance of N-heterocycles. ${ }^{\mathbf{1 0 - 1 2}}$ Thus developing synthetic methodologies of $\mathrm{C}-\mathrm{Se}$ bond formations on arenes and heteroarenes has become a research hotspot in recent times. In last two decades transition metal catalyzed cross-coupling reactions have become a powerful tool for the synthesis of aryl/heteroaryl selenides. ${ }^{13}$ However, use of expensive and in some cases toxic metal salts, ligands, harsh conditions, high temperature etc. were the serious limitations of those protocols.

Beletskaya and Ananikov et al summarized transition metal catalyzed $\mathrm{C}-\mathrm{S}, \mathrm{C}-\mathrm{Se}$ and $\mathrm{C}-\mathrm{Te}$ cross-coupling reactions. ${ }^{\mathbf{1 3}}$ Lenardao and coworkers highlighted different non- 

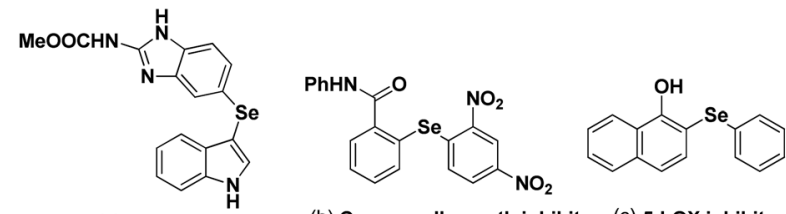

(a) Antitumor agent

(b) Cancer cell growth inhibitor (c) 5-LOX inhibitor
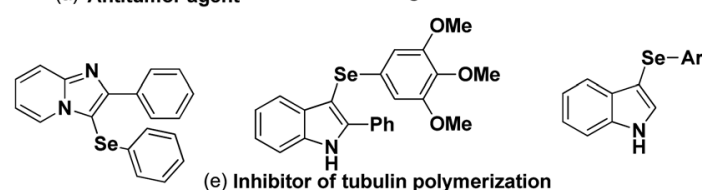

(e) Inhibitor of tubulin polymerization
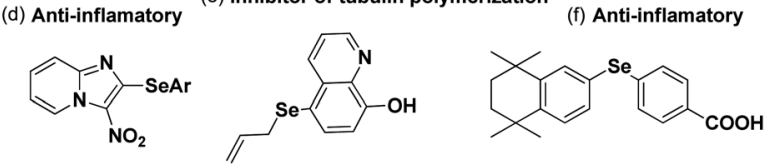

$\begin{array}{lll}\text { (g) Antimicrobial } & \text { (h) Treatment of Alzeheimer's disease }\end{array}$

(i) RAR agonist

Fig. 1 Examples of biologically important aryl/heteroaryl selenides.

conventional reaction media for the synthesis of organochalcogenides. ${ }^{14}$ Ranu and coworkers have summarized microwave assisted protocols for the synthesis of organochalcogenides..$^{15} \mathrm{~A}$ review based on application of diselenides for the synthesis of heteroaryl selenides was reported by Arsenyan et al. which mostly covered transition metal catalyzed protocols along with a few metal free electrophilic selenylations. ${ }^{16}$ In search of developing environment friendly and economic protocols for the assembly of aryl/heteroaryl C-Se/CTe bonds, a number of transition metal catalyst free protocols have been developed in last decade for the synthesis of aryl and heteroaryl selenides under sustainable conditions. To the best of our knowledge no exclusive review is present till date in this emerging field which covered all the well explored methodologies with broad substrate scopes for the synthesis of aryl and heterocyclic selenides and tellurides under metal catalyst free conditions. Thus here in, we have highlighted the recent advances of transition metal catalyst free strategies for the C-Se and $\mathrm{C}-\mathrm{Te}$ bond formations in last decade towards the synthesis of aryl/heteroaryl selenides and tellurides by using several techniques such as conventional methods using greener solvents and reagents, microwave irradiation, ultrasound, ballmilling, visible light medium and electrochemical cell (Fig. 2).

\section{Under conventional method}

In the context of green chemistry, ionic liquids have appeared as a powerful solvent in last two decades due to their high boiling point, easy separation and recyclability. ${ }^{17}$ Lenardao and Alves

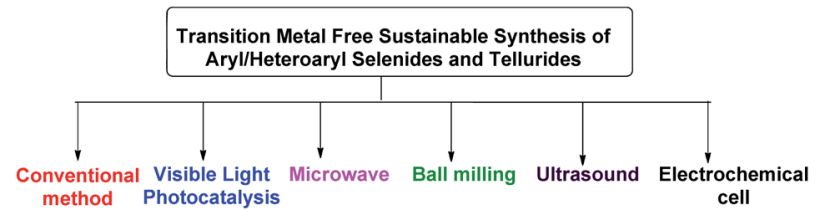

Fig. 2 Transition metal free sustainable tools for synthesis of aryl and heteroaryl selenides.

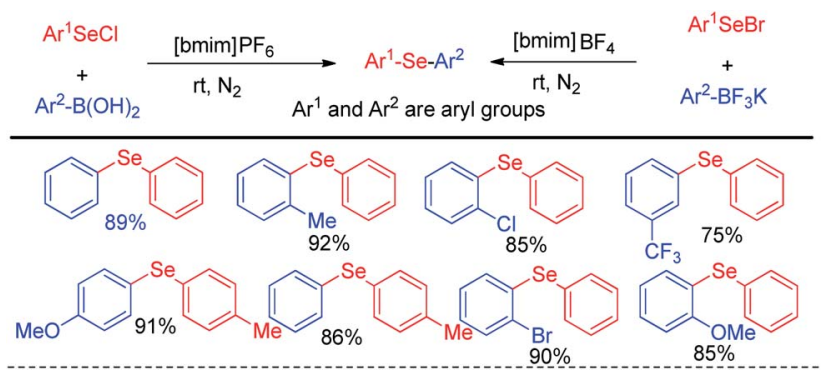

Scheme 1 Ionic liquid mediated synthesis of diaryl selenides from boronic acids and trifluoroborates.

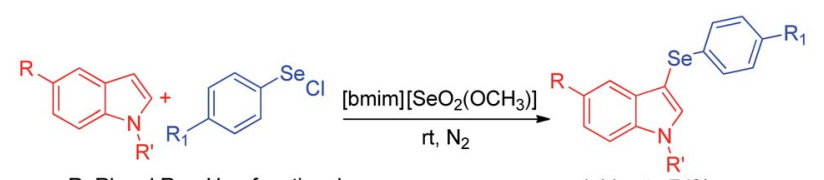

$R, R^{\prime}$ and $R_{1}=H$ or functional groups yield upto $74 \%$

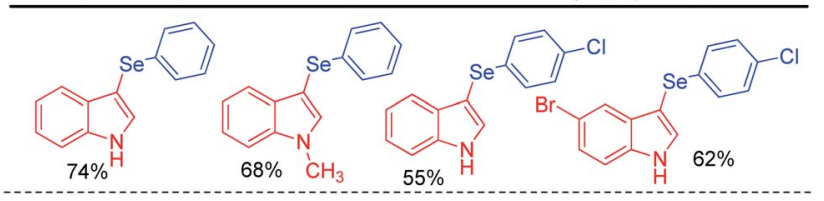

Scheme 2 3-Organoselenylation of indoles in ionic liquid.

et al. in 2011 reported ionic liquid mediated reaction of aryl selenium chlorides/bromides with aryl boronic acids for the synthesis of large array of diaryl selenides under room temperature (Scheme 1). ${ }^{17}$ The authors also explored the reaction with aryl trifluoroborates, however the yield was lower in comparison to the reactions with aryl boronic acids. The authors have managed to recycle the ionic liquid solvent for five times without any appreciable loss of yield.

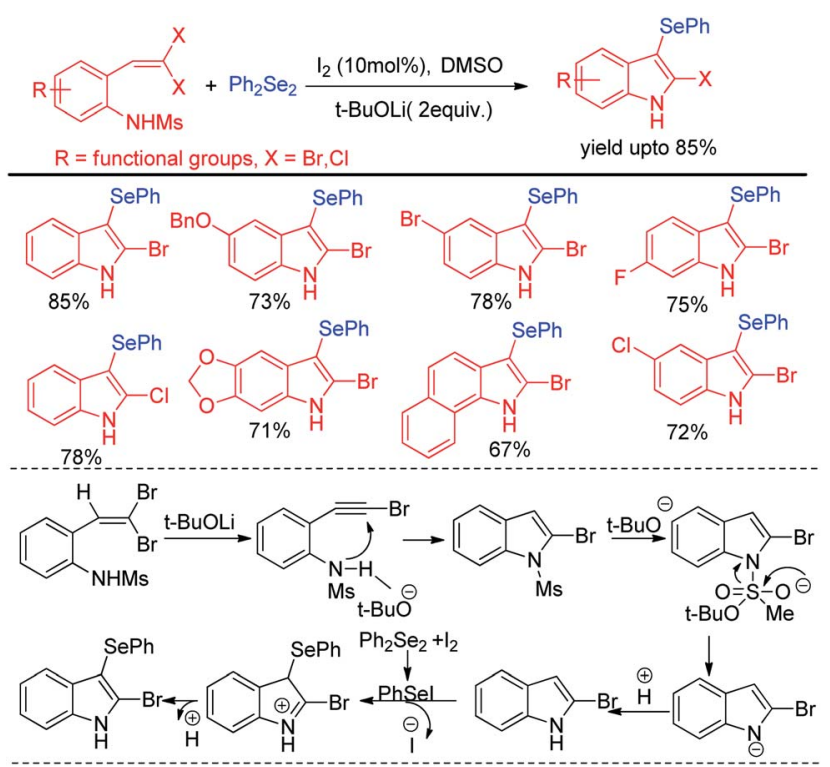

Scheme 3 lodine catalyzed synthesis of 2-bromo-3-selenyl-indoles by tandem reaction. 


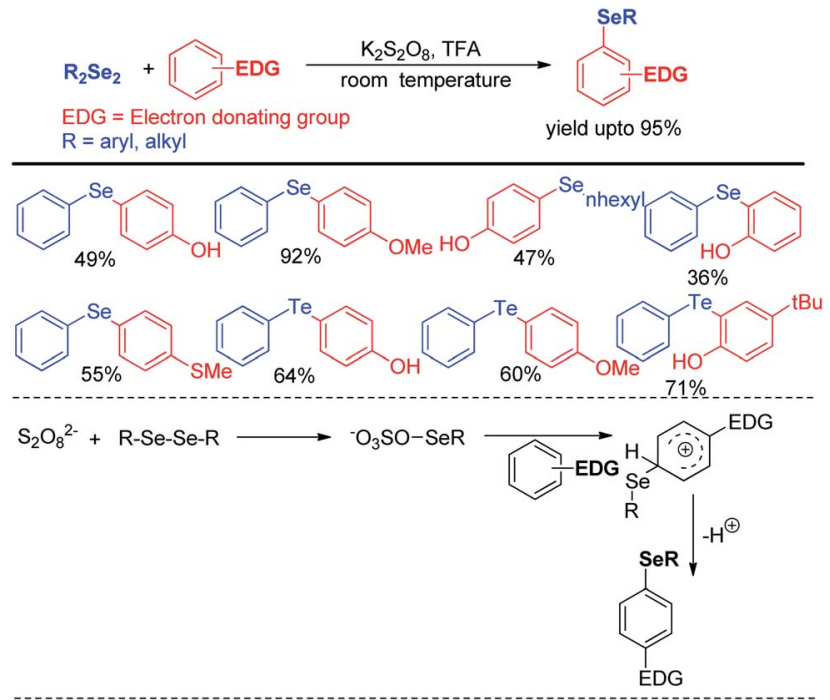

Scheme $4 \quad \mathrm{~K}_{2} \mathrm{~S}_{2} \mathrm{O}_{8}$ mediated electrophilic selenylation of electronrich arenes.

The idea of electrophilic selenylation by using aryl selenium halides as electrophiles was further nicely applied by the same group towards 3 -organoselenylation of indoles (Scheme 2). ${ }^{18}$ The authors have used selenium based ionic liquid [bmim] $\left[\mathrm{SeO}_{2}\left(\mathrm{OCH}_{3}\right)\right]$ as solvent.

Wang and co-workers have explored synthesis of 2-bromo-3selenyl-indoles through iodine catalysed tandem reactions of 2(gem-dibromo-vinyl)- $N$-methylsulfonylanilines with diselenides by using tBuoLi in DMSO solved under $110^{\circ} \mathrm{C}$ heating in sealed tube (Scheme 3)..$^{19}$ The reaction mechanism was proposed based on the synthesis of 2-bromoindole in presence of base which underwent selenylation in the electron rich 3-position with organodiselenides through the formation of active electrophile PhSeI by iodine.

Reaction with electron rich arenes and daryldiselenides was nicely explored by Kumar and co-workers to access diarylchalogenides using $\mathrm{K}_{2} \mathrm{~S}_{2} \mathrm{O}_{8}$ (Scheme 4). ${ }^{20}$

Arenes with different electron donating groups give moderate to high yields by electrophilic selenation at the -ortho or -para position w.r.t. the activating group in the aromatic ring. The mechanism was proposed by activation of diselenides with potassium persulfate as an oxidant to form an active intermediate which underwent electrophilic attack by electron-rich

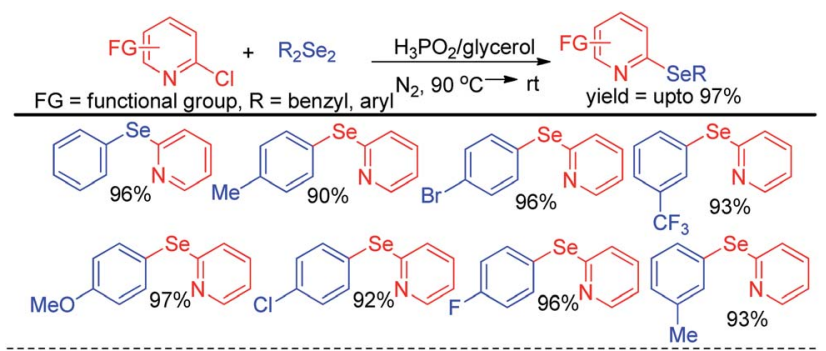

Scheme 5 Synthesis of 2-organoselanyl pyridines by using $\mathrm{H}_{3} \mathrm{PO}_{2}$ as reducing agent in glycerol medium.

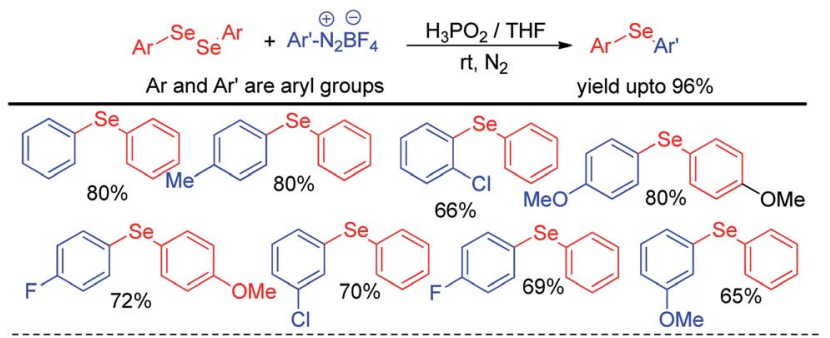

Scheme $6 \quad \mathrm{H}_{3} \mathrm{PO}_{2}$ driven synthesis of diaryl selenides from aryl diazonium salts.

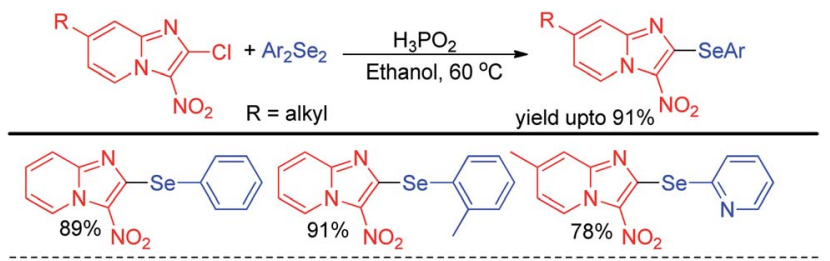

Scheme $7 \quad \mathrm{H}_{3} \mathrm{PO}_{2}$ mediated organoselenation of imidazopyridines.

arenes to form the desired product after proton elimination. The authors also have explored the scope of this reaction for the synthesis of diarylsulphides and tellurides. Alves et al. has reported $\mathrm{H}_{3} \mathrm{PO}_{2}$ mediated synthesis of 2-organoselanyl pyridines by reacting 2-chloropyridines with organodiselenides under glycerol medium (Scheme 5). ${ }^{21}$ The authors successfully recycled the $\mathrm{H}_{3} \mathrm{PO}_{2}$ /glycerol medium up to four cycles without appreciable loss of yield, however considerable loss of yield was found in $5^{\text {th }}$ and $6^{\text {th }}$ cycle. The reaction successfully synthesized a library of pyridine based selenides under sustainable conditions.

The same group later explored $\mathrm{H}_{3} \mathrm{PO}_{2}$ mediated simple reaction of aryl diazoniumtetrafluoroborate with diaryldiselenides for the synthesis of various diaryl selenides under room temperature in THF (Scheme 6). ${ }^{22}$ The authors reported in situ formation of phenyl selenol which acted as nucleophile and attacked aryl diazonium fluoroborate to form the product. The reaction was explored with several substituents in the aromatic ring of both diaryldiselenides and aryl diazoniumtetrafluoroborate salts.

The idea of activating diselenides by $\mathrm{H}_{3} \mathrm{PO}_{2}$ for performing nucleophilic selenation in aromatic ring was further applied by

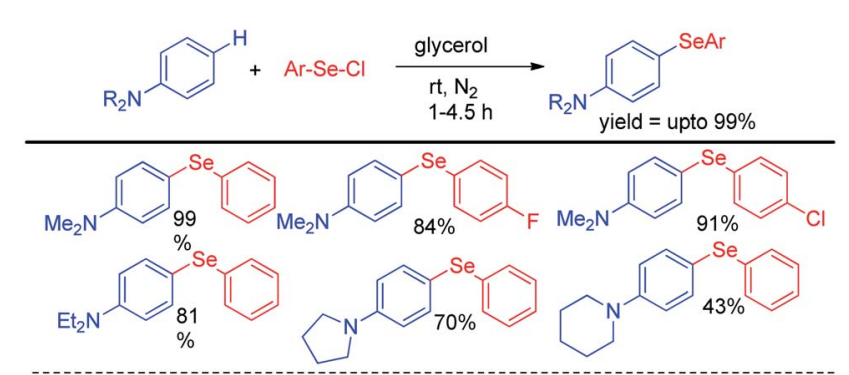

Scheme 8 Synthesis of aryl selenyl anilines under base free conditions. 


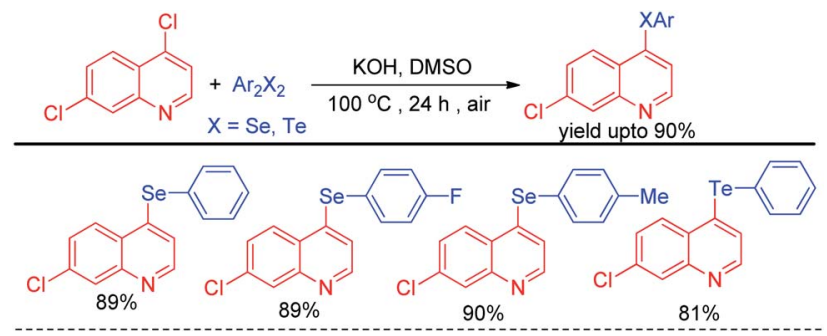

Scheme 9 Synthesis of quinoline selenides and tellurides via $S_{N} A r$ reaction.

Sharma and Bhasin et al. for organoselenation of electron deficient imidazopyridines (Scheme 7). ${ }^{23}$

Lenardao et al reported $\mathrm{C}-\mathrm{H}$ selenylation of aromatic tertiary amines by aryl selenyl chlorides under base free conditions in glycerol medium (Scheme 8). ${ }^{24}$ The reactions followed usual $\mathrm{S}_{\mathrm{N}} \mathrm{Ar}$ mechanistic path. Both cyclic and acyclic amines substituted aromatic rings were found to react with aryl selenyl chlorides under the reaction conditions however yields were found lowered in case of cyclic amines substitutedarenes.

Alves et al. reported synthesis of selenium and tellurium substituted quinoline derivatives by the $\mathrm{S}_{\mathrm{N}} \mathrm{Ar}$ reaction of 4,7dichloroquinoline with diselenides in presence of $\mathrm{KOH}$ (Scheme 9). ${ }^{25}$

In 2014, Braga et al. have developed $\mathrm{K}_{2} \mathrm{CO}_{3}$ driven selenylation in 1,3,4-oxadiazoles in DMSO solvent under $100{ }^{\circ} \mathrm{C}$ heating condition (Scheme 10). ${ }^{26}$ The acidic hydrogen in the 1,3,4-oxadiazoles was abstracted by base and nucleophilic substitution towards diselenide resulted the desired product.

Hajra and co-workers have reported synthesis of 3-phenylselenyl imidazo[2,1- $b]$ pyridine by selenylation of several substituted imidazo[1,2-a]pyridine molecules in PEG : $\mathrm{H}_{2} \mathrm{O}$ solvent $(1: 3)$ under base free conditions in room temperature (Scheme 11). ${ }^{27}$ Phenyl selenyl bromide was used as electrophile and the reaction followed a nucleophilic substitution mechanism. A library of substituted imidazo[1,2- $a]$ pyridine molecules bearing several substituents in the aromatic ring e.g. $-\mathrm{Me},-\mathrm{F}$, $-\mathrm{Cl},-\mathrm{Br},-\mathrm{CF}_{3}$ etc. underwent selenylation under this condition. The protocol was also successful for selenylation of imidazo[2,1b]thiazole.

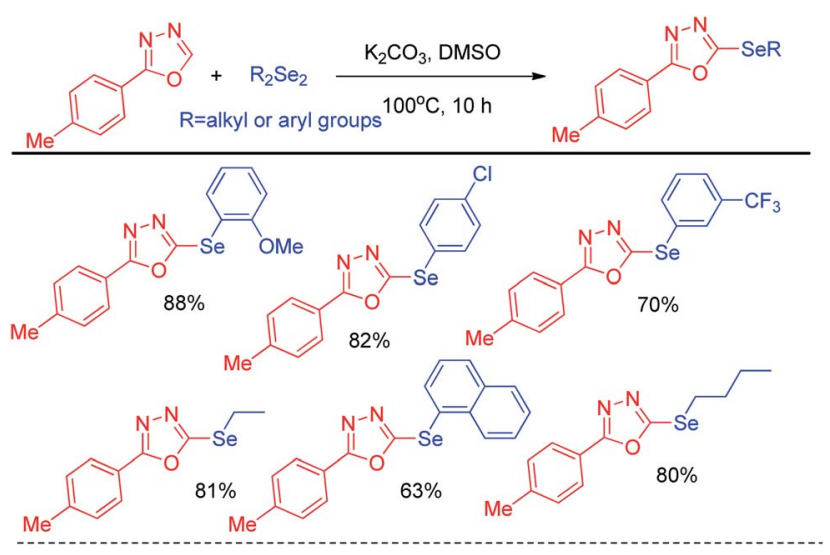

Scheme $10 \quad \mathrm{~K}_{2} \mathrm{CO}_{3}$ promoted selenylation in 1,3,4-oxadiazoles.

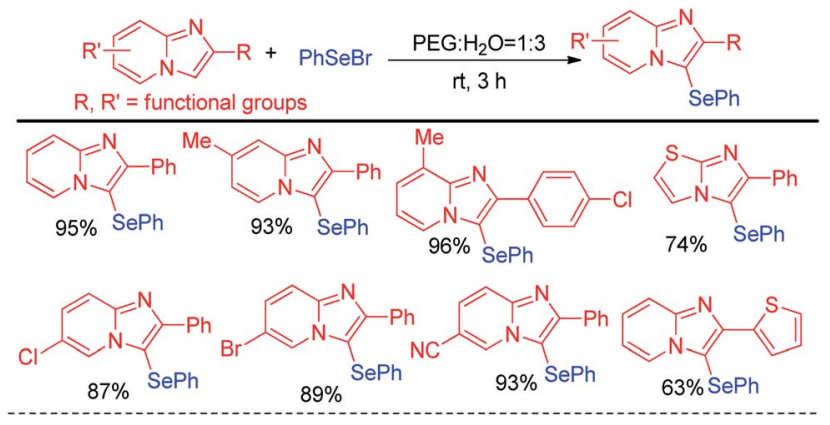

Scheme 11 Phenyl selenylation of imidazo[1,2-a]pyridine and imidazo [2,1-b]thiazole.

The concept of Hajra et al. of using organoselenium halide as electrophile in synthesizing selenolated heteroarenes was further designed atom economically by Braga and co-workers who latter reported organoselenylation in imidazo[1,2- $a]$ pyridines via electrophilic aromatic substitution with diselenides by using catalytic amount of iodine in reaction medium which generated selenyliodide in situ in medium (Scheme 12). ${ }^{28}$ Here DMSO acted as oxidizing agent to regenerate $\mathrm{I}_{2}$ from iodide in reaction medium. Apart from daryldiselenides, dialkyl and diheteroaryl selenides were also successfully applied to reaction under the reaction conditions.

Ranu et al. have reported a synthesis of unsymmetrical diaryl selenides by calcium mediated aryl $\mathrm{C}-\mathrm{F}$ bond substitution in activated fluoroarenes (Scheme 13). ${ }^{29}$ Many diaryl selenide compounds bearing several electron withdrawing substituents in the aromatic ring were synthesized with this method in high yields. The authors have proposed an interesting mechanism involving a transmetalation process of aryl selenide from $\mathrm{Zn}$ (II) to $\mathrm{Ca}(\mathrm{II})$ to produce active nucleophile $\mathrm{Ca}(\mathrm{SeAr})_{2}$. The bond was activated by $\mathrm{Ca}$ (II) and thus underwent nucleophilic attack to form the product via six membered transition state which was established by DFT studies.

Aryl hydrazine hydrochlorides were successfully applied as synthons for the synthesis of unsymmetrical diaryl selenides by Mizuno et al. via base promoted one pot reaction with

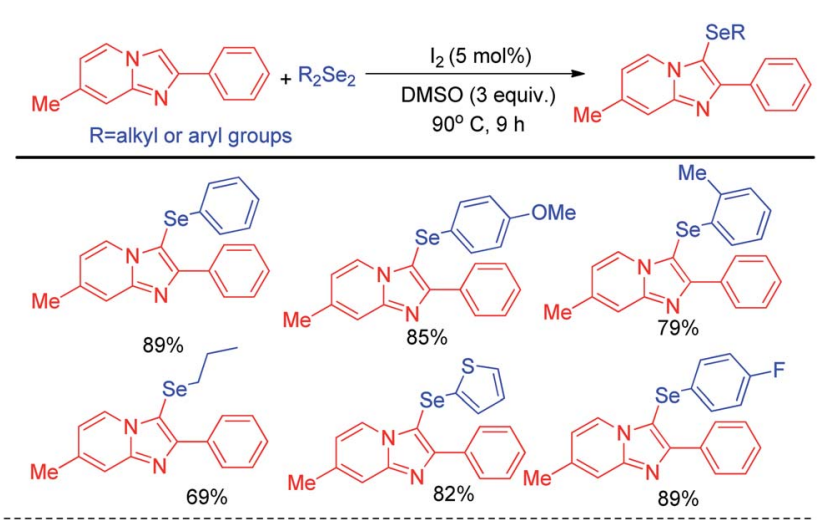

Scheme 12 lodine catalysed atom economical selenylation of imidazo [1,2-a]pyridine. 

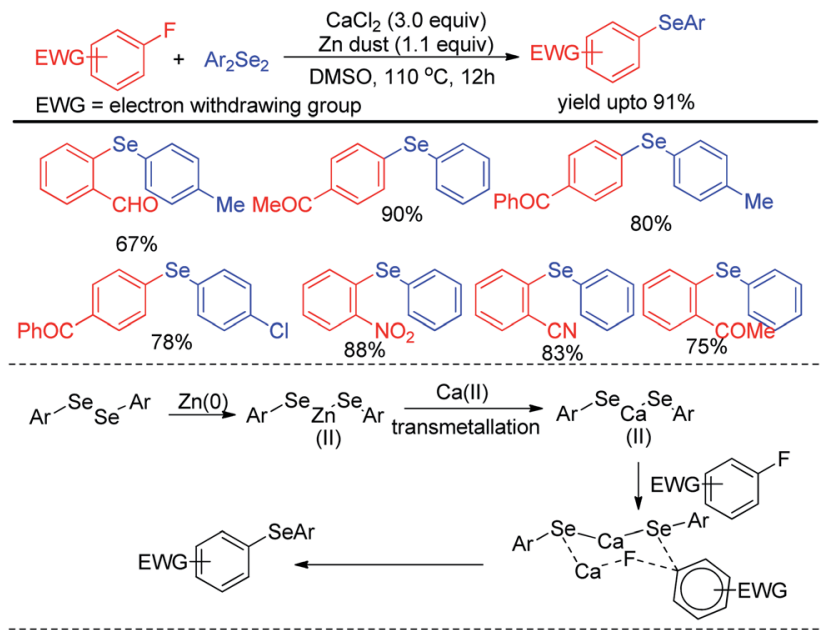

Scheme $13 \mathrm{CaCl}_{2}$ mediated selenation by $\mathrm{C}-\mathrm{F}$ bond activation in fluoroarenes.

diselenides using air as oxidant under $30{ }^{\circ} \mathrm{C}$ (Scheme 14). ${ }^{30}$ Several diarylselenide compounds having different substituents in the aromatic ring have been synthesized by this protocol in moderate to good yield. The authors proposed an air driven radical mechanistic approach for this reaction which underwent via forming aryl radical from aryl hydrazines.

Steven D. Townsend and co-workers has introduced diaryl iodonium triflates for the metal free one-pot synthesis of aryl selenocyanates by reacting with $\mathrm{KSeCN}$ in ethyl acetate under $80{ }^{\circ} \mathrm{C}$ heating (Scheme 15a). ${ }^{31}$

In addition to the synthesis of several aryl selenocyanates the protocol was further applied for the one pot synthesis of several important organoselenides by nucleophilic substitution in various electrophilic species such as alkynyl and benzyl iodonium salts, glycosyl bromide etc. (Scheme 15b). In the first step aryl selenocyanate was formed by the arylation of potassium selenocyante which was followed by reduction with $\mathrm{NaBH}_{4}$ and attack in electrophile. Hajra et al. introduced an sustainable protocol for the selenylation in furan ring of various 3substituted naphtho[2,1- $b]$ furans by reacting it with diselenides under room temperature by using sodium persulfate as oxidant

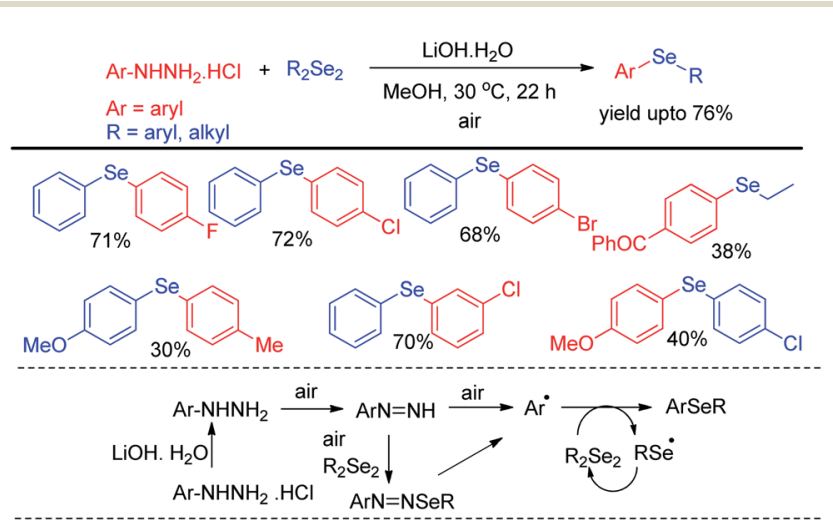

Scheme 14 Synthesis of diaryl-selenides from aryl hydrazine hrdrochlorides under air. (a)

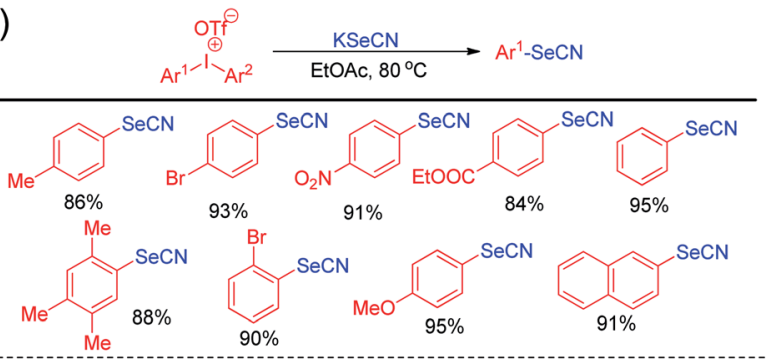

(b)

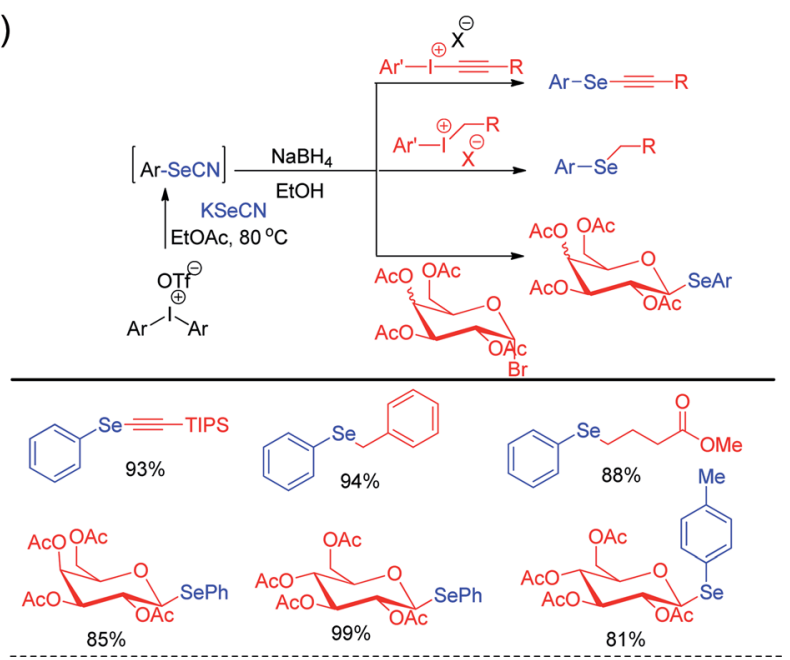

Scheme 15 (a) Synthesis of aryl selenocyanate by reacting KSeCN with diaryliodonium salts. (b) One pot synthesis of various organoselenides via in situ formation of aryl selenocyante.

(Scheme 16). ${ }^{32}$ However it was observed that alkyl substituted furan rings failed to initiate any conversion to the product.

Braga et al. have reported ammonium iodide $\left(\mathrm{NH}_{4} \mathrm{I}\right)$ catalyzed protocol for the synthesis of selenylimidazo[1,2-a]pyridines from $N$-heteroaryls and diphenyldiselenide in DMSO using acetic acid as an additive (Scheme 17). ${ }^{33}$ This protocol is highly efficient for the selenation of different 5-membered $N$ heteroaryls e.g. indole, imidazothiazole, indazole and imidazopyrimidine having different substituents in the aromatic ring.

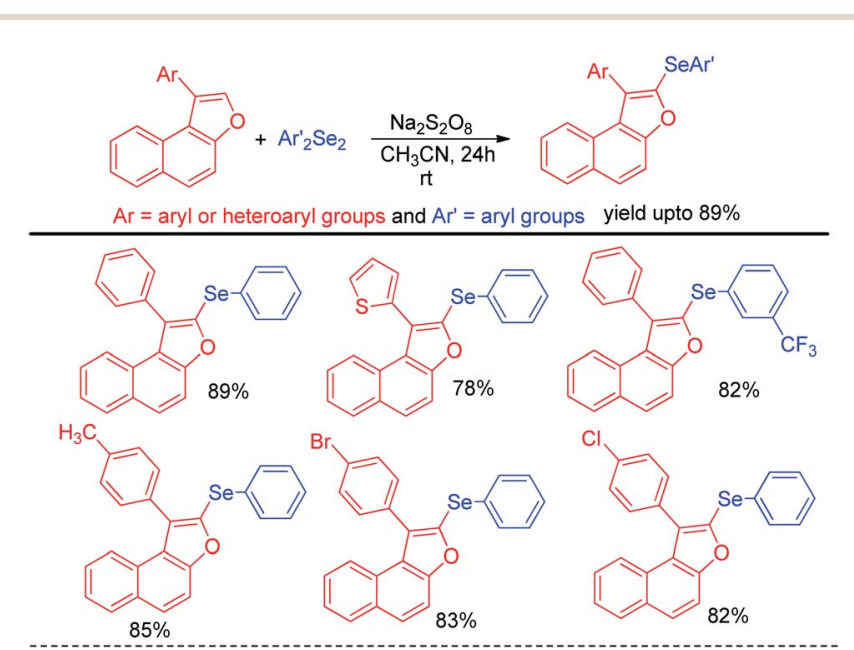

Scheme 16 Selenylation of substituted naphthofurans under rt. 


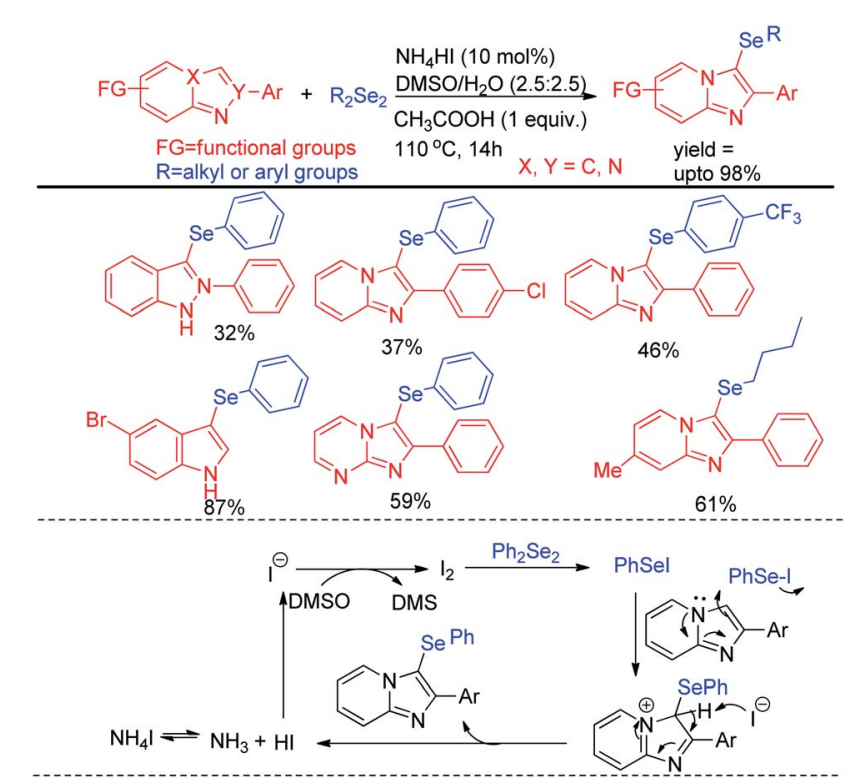

Scheme $17 \mathrm{NH}_{4} \mathrm{l}$ catalysed selenylation of $\mathrm{N}$-containing heteroarenes.

The reaction proceeded through the in situ formation of iodine by oxidation of iodide by DMSO which converted diselenide into active electrophile organo-seleniumiodide. Electrophilic attack by heteroarenes led to the formation of product and the resultant iodide took part in another cycle. Ranu et al. have reported an efficient method for the synthesis of bicyclic di-aryl and styrenyl/aryl selenides by using 2-naphthanol and diarylselenides/sterenylselenocyanate respectively without using any oxidant or additive at room temperature (Scheme 18)..$^{34}$

Selenation occurs at the 1-position of 2-naphthols through $\mathrm{C}-\mathrm{H}$ bond functionalization in dimethyl sulfoxide (DMSO) in presence of $\mathrm{Cs}_{2} \mathrm{CO}_{3}$ as base. A series of 2-naphthanol containing both electron donating and withdrawing groups reacts with both diaryldiselenide and vinyl selenocyante successfully to give corresponding napthtyl-aryl selenides and napthyl vinyl selenides respectively by following an electrophilic aromatic substitution mechanism in good to excellent yields. Jana and

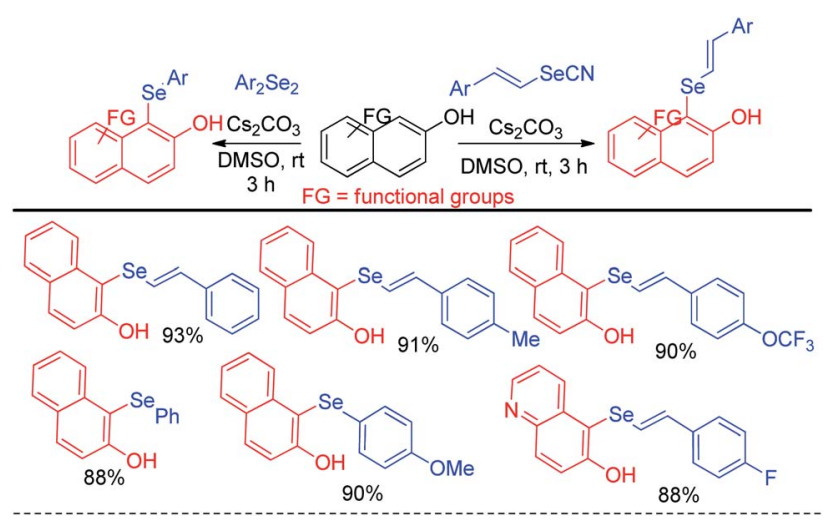

Scheme 18 C-1 selenylation in 2-hydroxy naphthalene derivatives under mild conditions.

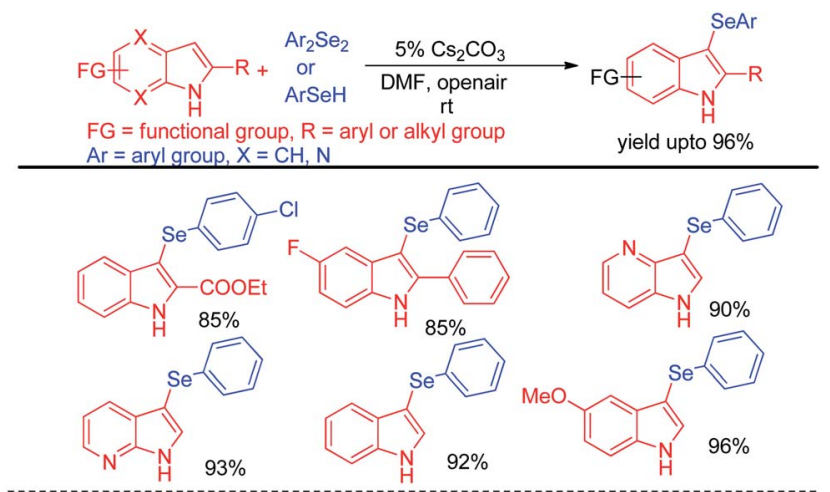

Scheme 19 Base mediated selenylation of N-heterocycles under air.

co-workers have reported an interesting base promoted selenylation in the electron rich position of indole systems with phenyl selenol under oxygen atmosphere in room temperature without using any external oxidant (Scheme 19). ${ }^{35}$ Aryl selenols with different substituents in the aromatic ring have been employed for the synthesis of library of aryl/heteroaryl selenides through Friedel-Crafts type electrophilic aromatic substitution in electron rich position of heteroarenes such as indole, $1 H^{-}$ pyrrolo[3,2-b]pyridine, $1 H$-pyrrolo[2,3-b]pyridine etc. The authors have proposed an ionic mechanism for this reaction which was established with the help of EPR studies.

Zhao and co-workers reported an acid catalyzed oxidative cleavage of Se-Se bonds of organodiselenides in presence of DEAD and applied this process for the reaction of aryl boronic acids with diselenides leading to the formation of a library of diaryl or aryl alkyl selenides (Scheme 20). ${ }^{36}$ Authors applied $\mathrm{BF}_{3}$ as Lewis acid for this reaction. The reaction was also explored with disulfides for the synthesis of organosulfides.

The concept of iodine catalysed activation of organodiselenides was successfully applied by Hajra et al. towards electrophilic selenylation of $2 H$-indazoles for the synthesis of a library of 3-(phenylselanyl)-2H-indazoles (Scheme 21). ${ }^{37}$ The reactions were performed under room temperature in absence of any solvent with large functional group compatibility in the aromatic rings of both reactants.

Yan et al. reported haloid salt (bromide and iodide) promoted protocol for the preparation of 4-selanylpyrazoles from $N$-protected pyrazoles in presence of hydrogen peroxide as oxidant in water at room temperature (Scheme 22). ${ }^{38}$

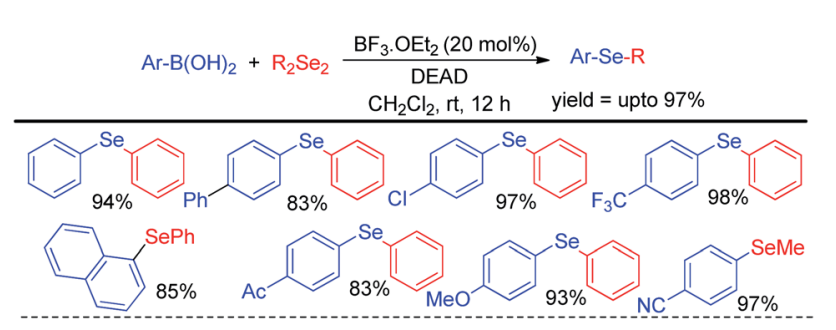

Scheme 20 Acid catalyzed reaction of boronic acids with diselenides in presence of DEAD. 


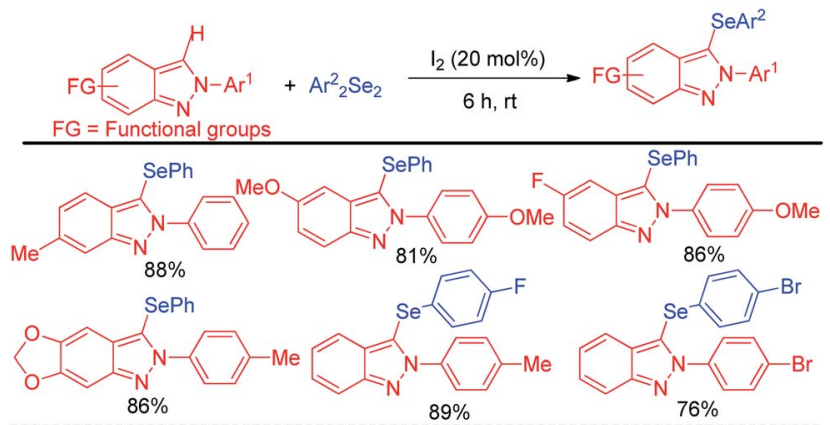

Scheme 21 lodine catalyzed selenylation in $2 \mathrm{H}$-indazoles under solvent free conditions.

The protocol was successful in synthesizing a series of 4selenyl pyrazoles in moderate to good yields. According to the authors haloid anion reacts with oxidant and forms molecular halogen which helped to break Se-Se bond during the reaction to form active electrophile $\mathrm{PhSeX}$ which underwent reaction following electrophilic aromatic substitution in pyrazoles. In 2019, Yunfei and co-workers have introduced synthesis of 4selenyl isocoumarins from $o$-(1-alkynyl)benzoates and (Z)-2alken-4-ynoates via in situ formation of organoselenium halides from organodiselenides and dichlorophenyliodonium salts (Scheme 23). ${ }^{39}$ The one pot strategy resulted regioselective synthesis of a library of 4 -selenyl isocoumarins in good to excellent yields under mild reaction conditions with high functional group compatibility.

The in situ formed organoselenium halide activated the triple bond in substrate and thus the intramolecular cyclization resulted the formation of product.

Billiard et al. developed an interesting strategy for the synthesis of fluoroalkylselenolated heteroarenes and heterocycles by involving in situ formed fluoroalkylselenylchloride into tandem cyclization with ortho-substituted alkynes (Scheme 24). ${ }^{40}$ Different fluoroalkylselenolated five [Scheme 24a] and six [Scheme 24b] membered heterocycles including benzofurans, benzothiophenes, isoquinolines, isocoumarins etc. were synthesized in good to excellent yields by this protocol under room temperature. Zengqiang Song and co-workers have developed a $\mathrm{C}\left(\mathrm{sp}^{2}\right)-\mathrm{H}$ selenation of different heteroacycles with

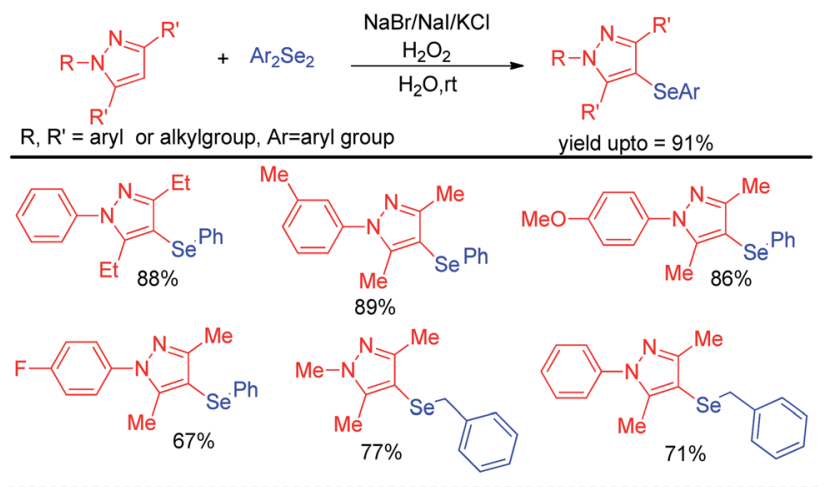

Scheme 22 Halide salt promoted synthesis of 4-selenyl pyrazoles.
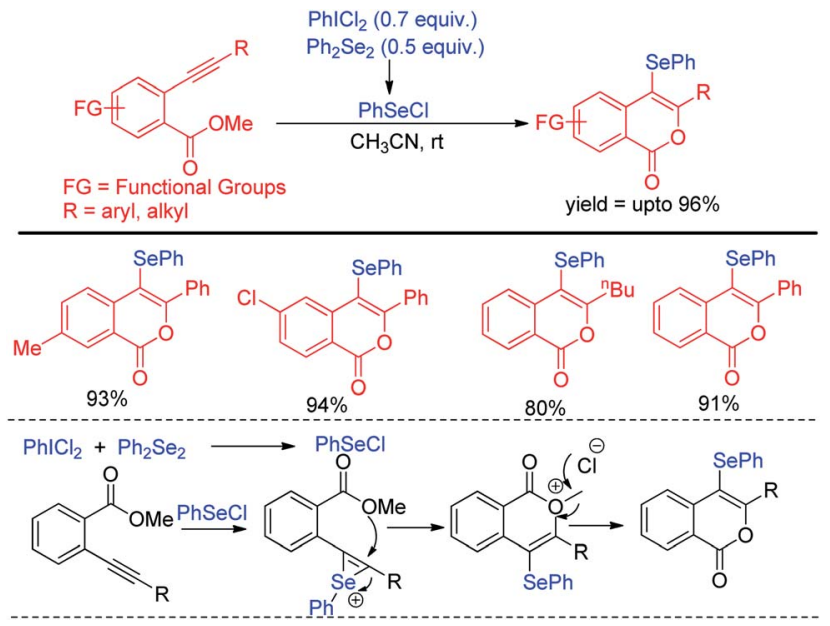

Scheme 23 One-pot regioselective synthesis of 4chalcogenylisocumarins.

diselenides (0.5 equiv.) NIS as catalyst and TBHP as additive (Scheme 25). ${ }^{41}$

A wide range of heteroarenes such as flavones, indoles, imidazo[1,2-a]pyridines, imidazo[2,1- $b]$ thiazoles underwent reaction with diaryl/alkyl/benzyl diselenides to produce good yields of products. A radical mechanistic approach for this reaction was proposed by the authors where tert-butylperoxyl or tert-butoxyl radicals are generated by NIS and take part in SET process from heteroarenes to initiate the reaction. Zhang and co-workers very recently reported an innovative idea of aryl Cheteroatom bond formations via $\mathrm{C}-\mathrm{N}$ bond cleavage using aryl ammonium salts as active electrophile (Scheme 26). ${ }^{42}$ The authors applied the idea in aryl C-Se bond formations by using organodiselenides in presence of $\mathrm{KBH}_{4}$ as base under room temperature. The authors proposed $\mathrm{S}_{\mathrm{N}} \mathrm{Ar}$ mechanism for the reaction. Although the reaction required activating electron

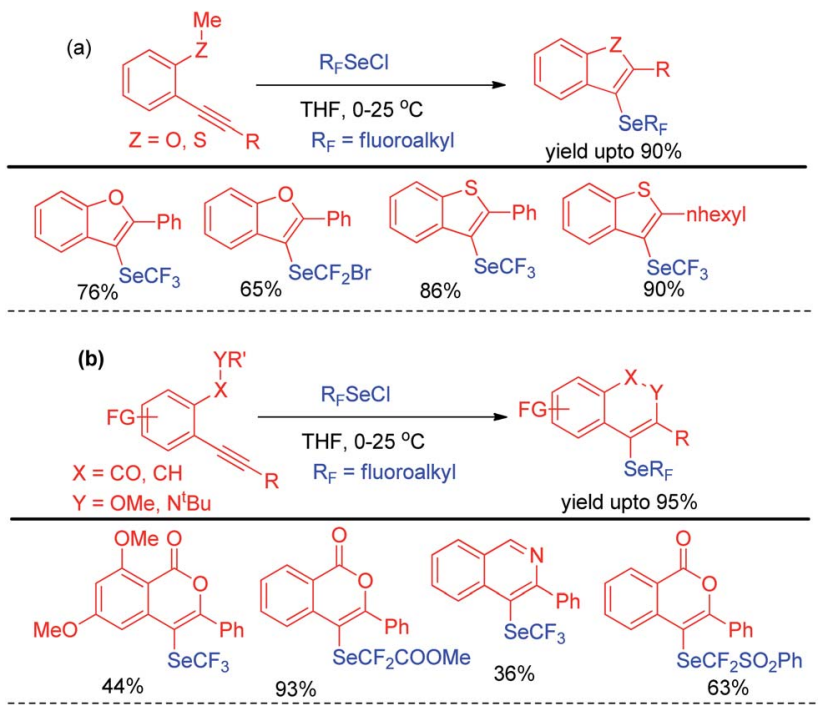

Scheme 24 Synthesis of fluoroalkylselenolated heterocycles under room temperature. 


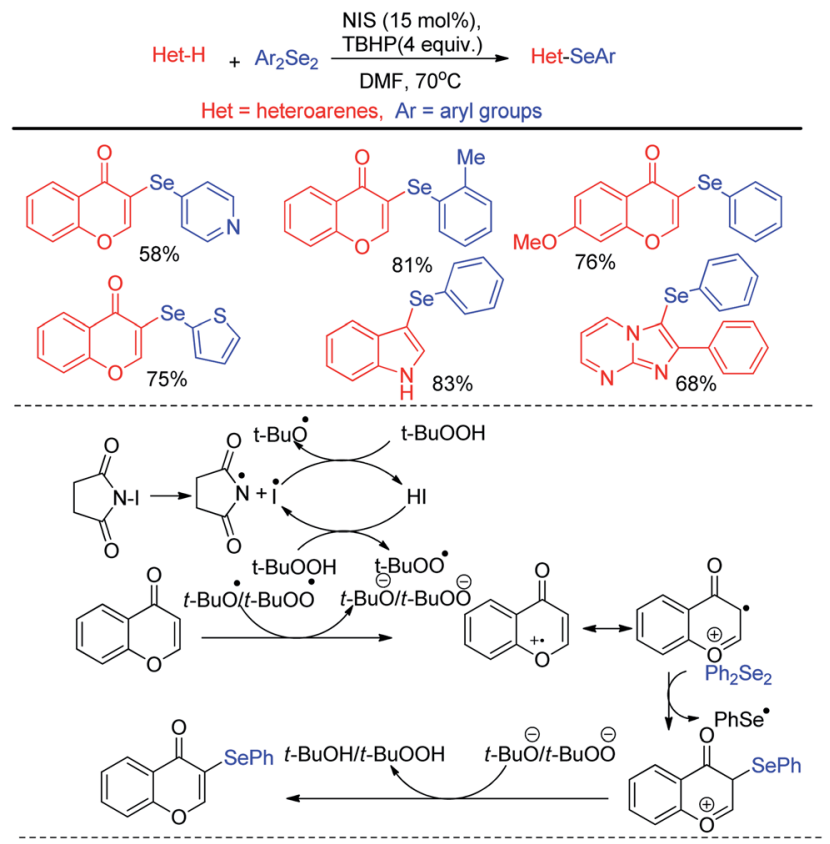

Scheme $25 \mathrm{I}_{2} /$ TBHP mediated $\mathrm{C}-\mathrm{H}$ selenation of heteroarenes in room temperature.

withdrawing substituents in aromatic ring to facile the reaction. The authors also explored the scope of the reaction by synthesizing selenium derivative of antibiotic drug sulfadiazine.

The same group later explored the aryl carbon-heteroatom bond formations by $\mathrm{C}-\mathrm{S}$ bond cleavage by using aryl sulfonium salts as electrophiles by $\mathrm{S}_{\mathrm{N}} \mathrm{Ar}$ mechanism. ${ }^{43}$ Thus the authors have explored aryl $\mathrm{C}-\mathrm{Se}$ bond formation by $\mathrm{C}-\mathrm{S}$ bond cleavage using organodiselenides in presence $\mathrm{KBH}_{4}$ as base like previous protocol under room temperature (Scheme 27). ${ }^{43}$ The authors only explored the scope of the reaction with para- $\mathrm{NO}_{2}$-phenyl sulfonium salts. Thus although the reaction condition is mild the protocol suffered from limited substrate scopes due to the requirement of presence of specific activating groups in aryl ring.

Zhao and co-workers recently reported $\mathrm{C}-\mathrm{H}$ selenation of cyclic alkanes and ethers by using selenium powder in presence of 4 equivalent DCP as oxidant (Scheme 28). ${ }^{44}$ The reaction

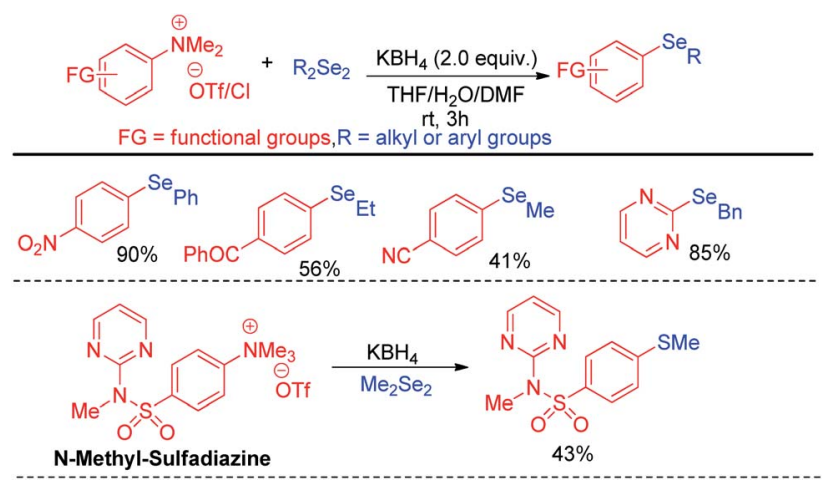

Scheme 26 Aryl $\mathrm{C}-$ Se bond formation by $\mathrm{C}-\mathrm{N}$ bond cleavage from aryl ammonium salts.

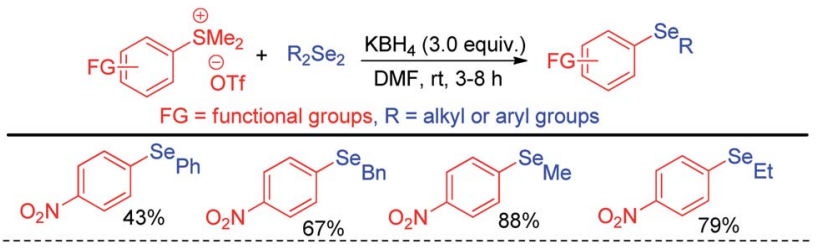

Scheme 27 Aryl C-Se bond formation by $\mathrm{C}-\mathrm{S}$ bond cleavage from aryl sulfonium salts.

followed a radical mechanism where DCP acted as radical initiator. The reaction was found to form trace amount of product in presence of TEMPO. Cyclic alkanes such as cyclopentane, cyclohexane, cycloheptane, cyclooctane was found to produce moderate to good yields of 3-selenoalkyl imidazopyridines under the reaction conditions. Cyclic ethers such as 1,4dioxane, THF etc. were also found to react successfully under the reaction conditions.

Selenosulfonates were introduced as effective organoselenium source by Wang and Ji et al. for the synthesis of 3selenylimidazo[1,2-a]pyridine derivatives via iodine promoted one pot multicomponent reaction with pyridine-2-amines and aryl methyl ketones (Scheme 29). ${ }^{45}$ Selenosulfonate in presence of iodine produced organoselenium cation intermediate which underwent electrophilic attack by in situ formed imidazo[1,2-a] pyridine to form the product. Very recently Lee and co-workers have reported a reaction of aromatic amines with diaryldiselenides in presence of ${ }^{t} \mathrm{BuONO}$ as diazotizing agent under neat conditions in room temperature (Scheme 30). ${ }^{46}$ The authors were able to synthesize a number of diaryl selenides

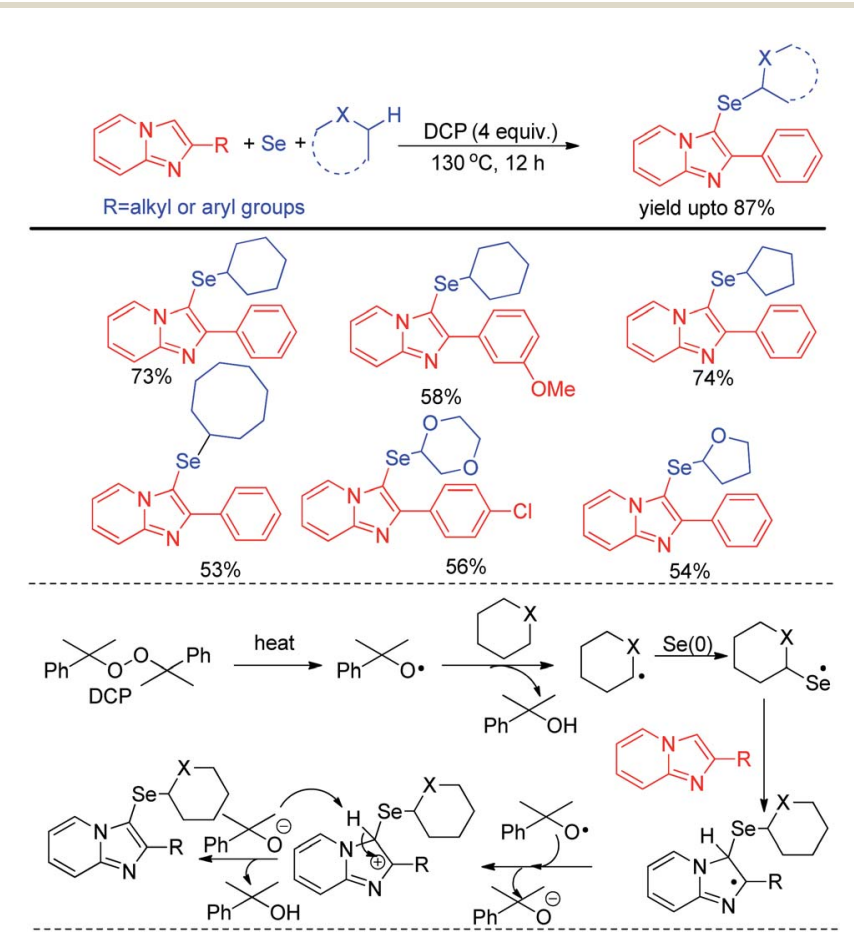

Scheme 28 DCP mediated $\mathrm{C}-\mathrm{H}$ selenation of imidazopyridines under room temperature. 

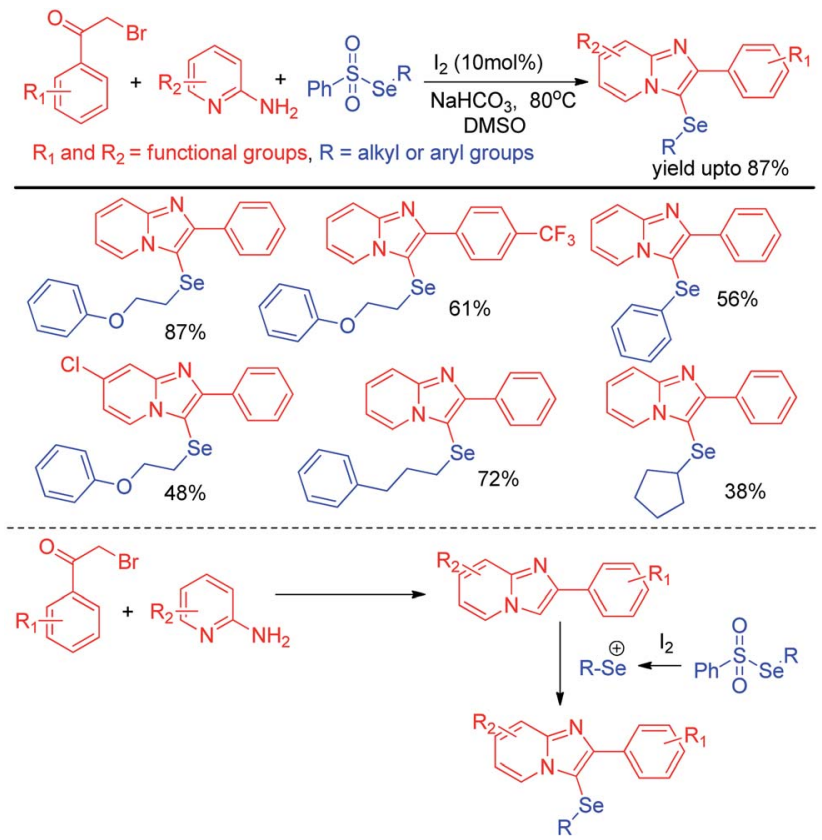

Scheme 29 lodine catalysed one pot synthesis of 3-selenylimidazo [1,2-a]pyridine.

with different substituents in aromatic ring. However blue light irradiation was required in case of sulphides.

Very recently Schumacher \& Silva et al. have revealed the role of selectfluor in generating electrophilic selenium species from organodiselenides and thus explored its application for the synthesis of 3-selanylbenzo[b]furans via electrophilic cyclization of 2-organoalkynyl anisoles under nitrogen atmosphere (Scheme 31). ${ }^{47}$ diaryl, di-heteroaryl, dialkyl diselenides were compatible under the reaction conditions to produce moderate to excellent yields of products. Organoselenides in presence of selectfluor produced organoselenium fluorides as active electrophile which underwent electrophilic attack by triple bond to form intermediate A. Finally desired product was obtained by intramolecular cyclization from $\mathbf{A}$. The authors also explored the scope of this reaction in synthesizing 3-selenylindoles from 2-organoalkynyl anilines.

The concept of activation of organodiselenides by selectfluor was further applied by the same author towards the $\mathrm{C}-\mathrm{H}$ selenation of heteroarenes and electron rich aromatic compounds (Scheme 32). ${ }^{48}$

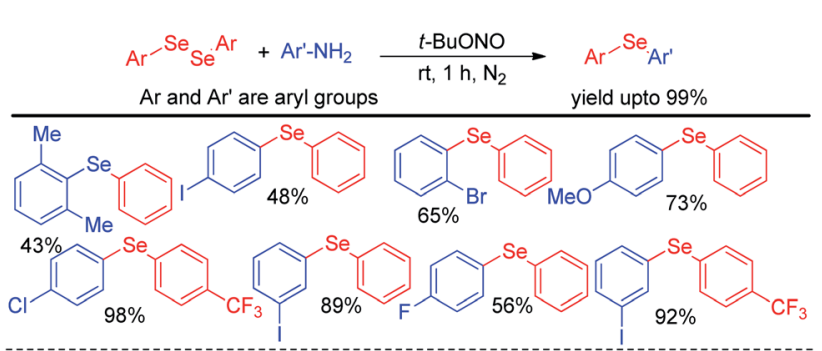

Scheme 30 Synthesis of diaryl selenides from aromatic amines under solvent free conditions.

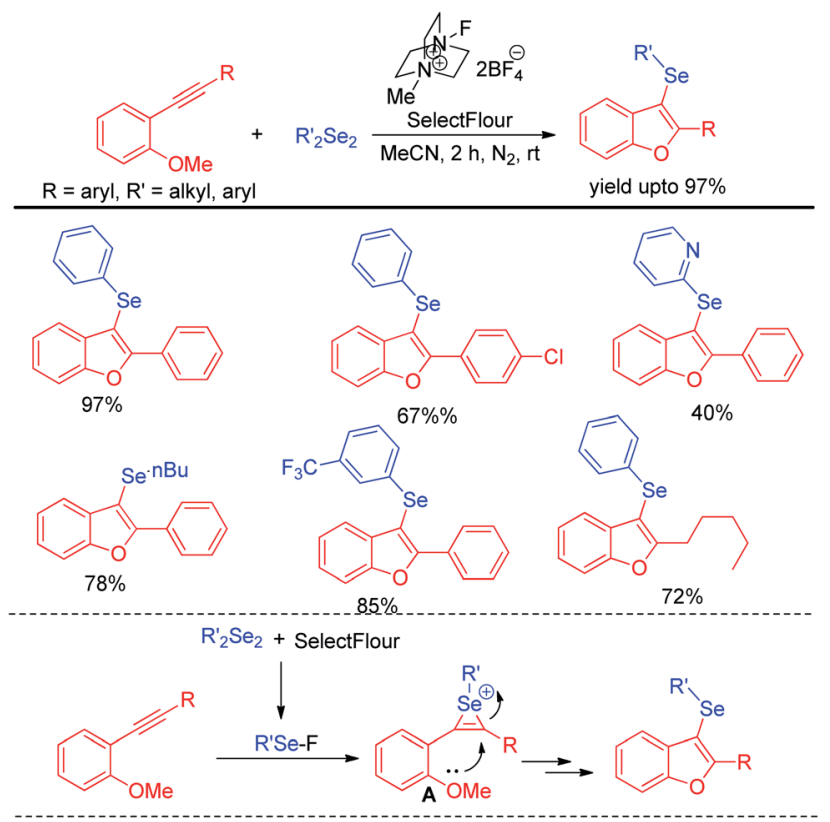

Scheme 31 Selectfluor promoted synthesis of 3-selanylbenzo[b] furans.

The reactions were performed under air in room temperature in acetonitrile solvent. A large array of heteroarenes such as, imidazo[2,1- $b]$ thiazole, imidazo[2,1- $b]$ pyridine, indole, pyrazole, thiazole etc. underwent selenation at their electron rich positions successfully by following an electrophilic substitution mechanism. However oxazole was found to be inactive towards electrophilic selenation under this protocol.

\section{Under photoinduction or visible light medium}

In last decade visible light has appeared as a sustainable and economic power source which initiates a large array of organic reactions based on $\mathrm{C}-\mathrm{C}$ and $\mathrm{C}$-heteroatom bond formations in presence of transition metal complexes or organic dyes as photocatalysts under room temperature. Such protocols are highly green as the energy source is non-toxic, highly abundant

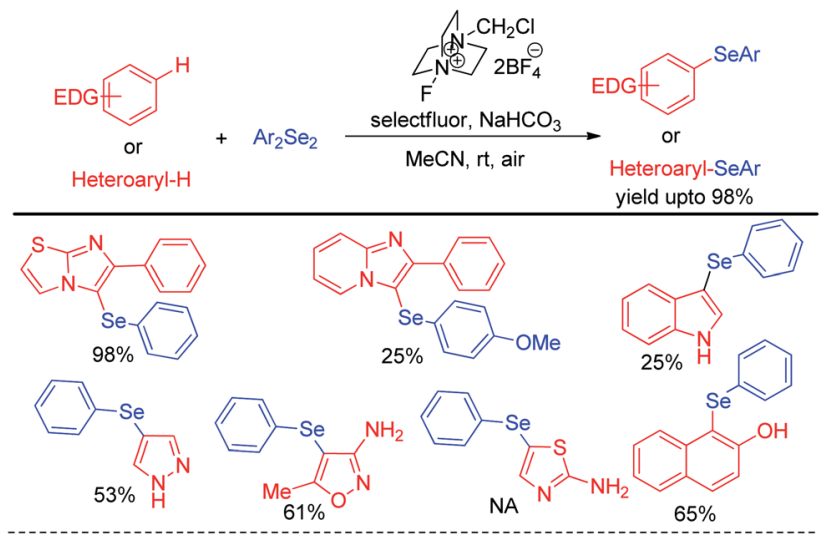

Scheme 32 Selectfluor activated $\mathrm{C}-\mathrm{H}$ selenation of heteroarenes and electron-rich arenes. 


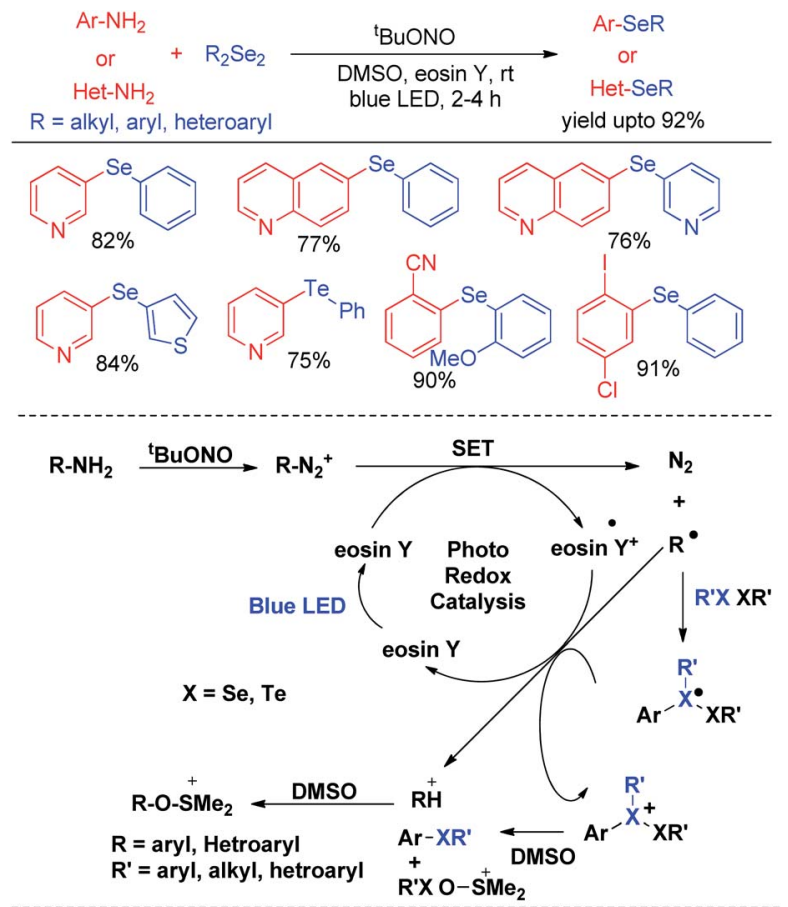

Scheme 33 Visible light photocatalyzed synthesis of diatyl/heteroaryl selenides/tellurides from aromatic amines.

and without any waste generating unlike burning of fossil fuels. Hence the concept of visible light photocatalysis was applied for the synthesis of aryl and heteroaryl selenides and tellurides by $\mathrm{C}-\mathrm{Se} / \mathrm{C}-\mathrm{Te}$ bond forming reactions in recent years. In 2014, Ranu and co-workers have developed one pot synthesis of unsymmetrical diaryl/heteroaryl selenides from aryl/heteroaryl amines by in situ diazotation with and tert-butyl nitrite under blue LED light using eosin $\mathrm{Y}$ as photocatalyst at room temperature (Scheme 33). ${ }^{49}$ The reactions are high yielding which makes the procedure suitable for synthesis of a wide range of aryl/heteroaryl (e.g. pyridine, thiophene, quinoline, thiazole

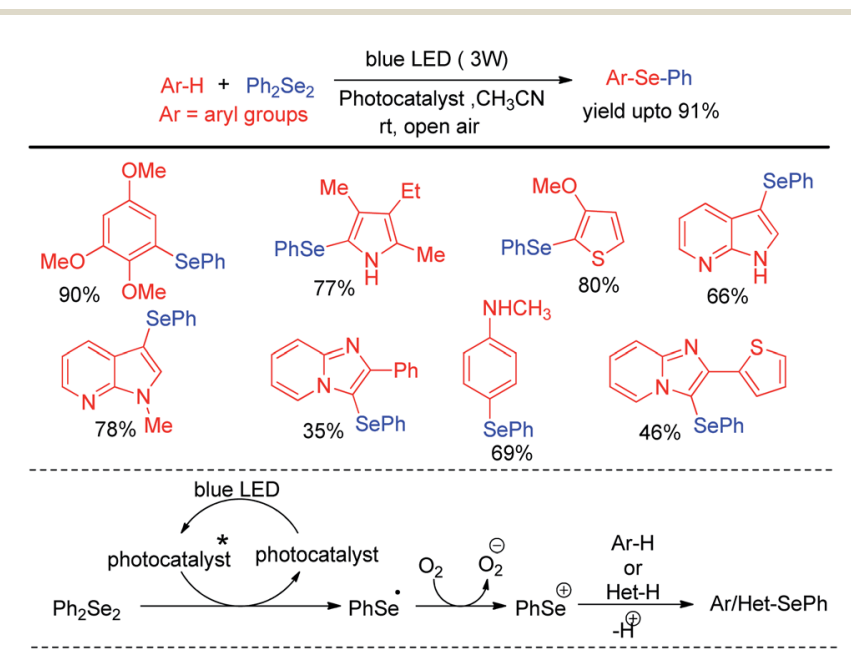

Scheme 34 Visible light mediated $\mathrm{C}-\mathrm{H}$ selenation of electron rich arenes/heteroarenes under air. etc.) selenides. They also explored the scope of this methodology for the synthesis of diaryl tellurides and sulphides. Differential bi-selenation in the same aromatic ring was also performed by starting with nitroanilines. The authors have proposed the DMSO driven radical mechanistic approach based on single electron transfer from photocatalyst under blue light for this reaction. The authors found that the reaction was quenched in presence of TEMPO under reaction conditions.

Liu and co-workers reported $\mathrm{C}-\mathrm{H}$ selenation of electron rich arenes and heteroarenes with diselenides under aerobic oxidation in room temperature (Scheme 34$).^{50}$ The authors used Ir-complex (bis[2-(4,6-difluorophenyl)pyridinato- $C 2, N]$ (picolinato)iridium(III)) (Flrpic) as photocatalyst for this reaction. However the authors also established that the reaction was also successful with organocatalyst $\mathrm{Na}_{2}$-eosin-Y which was found less efficient by a marginal scale under the reaction conditions.

Different electron rich arenes and heteroarenes such as thiophene, pyrrole, indoles, imidazopyridine, methoxybenzenes were found to undergo $\mathrm{C}-\mathrm{H}$ selenation to produce good to excellent yields. Less electron rich arenes such as azulene was also found to undergo selenation under the reaction conditions with lower yield production. The authors established the mechanism on the basis of nucleophilic attack by arenes on $\mathrm{PhSe}+$ which was generated from diselenide by single electron transfer from photocatalyst under blue-LED followed by oxidation by oxygen. Braga et al. have developed visible light photocatalyzed synthesis of selenyl indole, selenylimidazoles and selenylarenes via direct $\mathrm{C}\left(\mathrm{sp}^{2}\right)-\mathrm{H}$ functionalisation by using Rose Bengal as photocatalyst (Scheme 35$).{ }^{51}$ This is an atom economic \& regioselective reaction catalysed by Rose Bengal under blue LEDs using $\mathrm{CH}_{3} \mathrm{CN}$ solvent at room temperature under both argon and oxygen atmosphere. Different kinds of heterocycles such as indoles, benzopyrazines, imidazo[1,2-a]

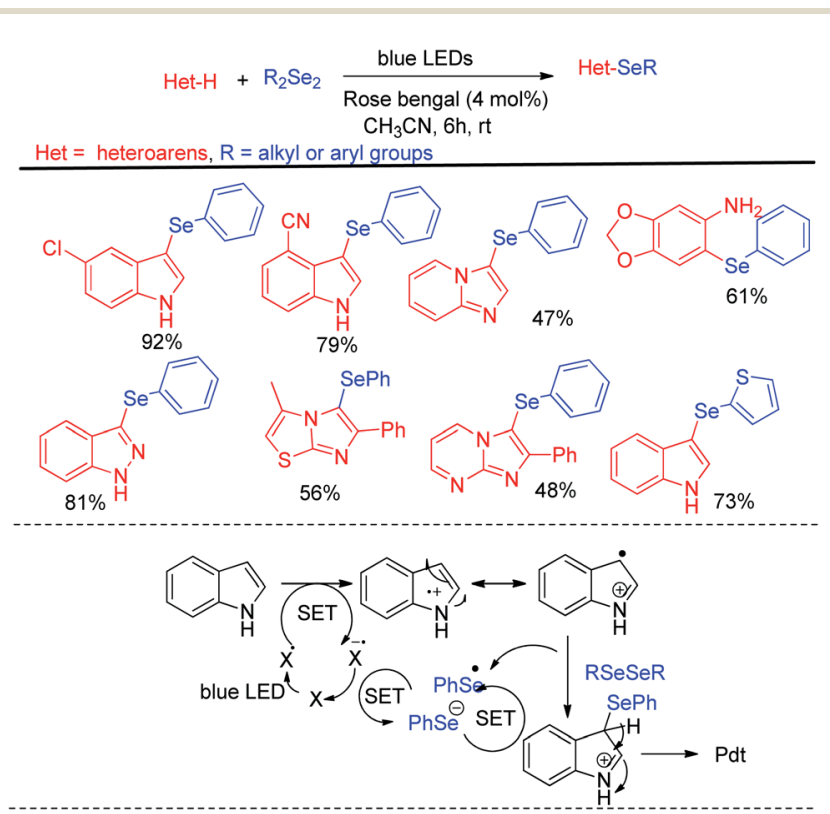

Scheme 35 Rose Bengal catalysed $\mathrm{C}-\mathrm{H}$ selenation of heteroarenes under room temperature. 

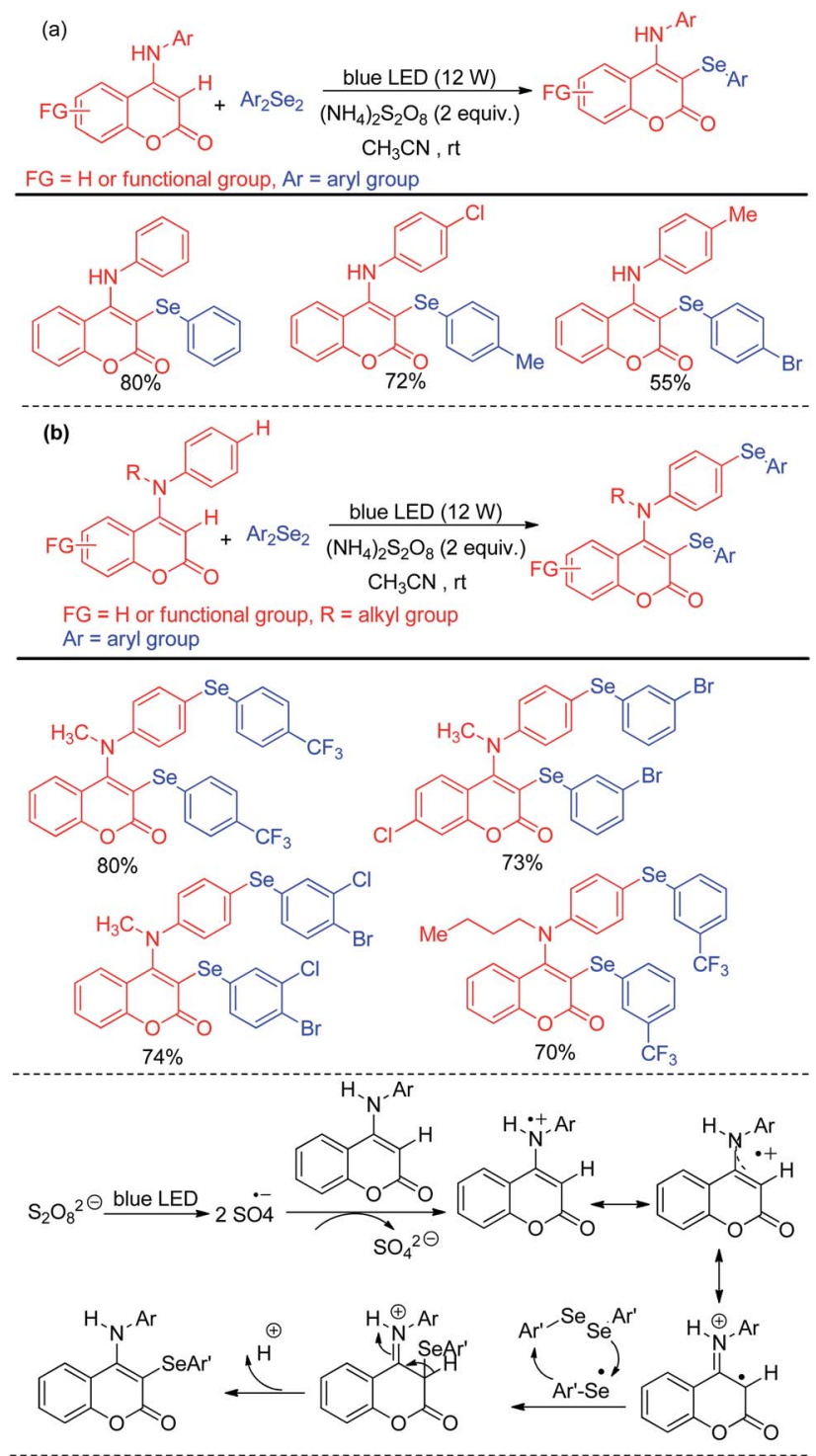

Scheme $36\left(\mathrm{NH}_{4}\right)_{2} \mathrm{~S}_{2} \mathrm{O}_{8}$ driven selenylation of 4-amino coumarins under blue light.

pyridines, imidazo[1,2- $a]$ pyrimidines, imidazo[2,1- $b]$ thiazoles and electron rich arenes underwent reaction with diselenides to produce good to excellent yields following a photocatalyzed radical mechanistic pathway. The authors failed to initiate any conversion to the products in case of 3-substituted indoles. However several $N$-protected indoles were found to generate selenated products in good yields. The reaction failed to initiate any conversion to the product with ditellurides and disulfides.

Yang et al. have reported visible light mediated regioselective selenylation of 4 -amino substituted coumarin derivatives by diselenides without using any photocatalyst. $\mathrm{CH}_{3} \mathrm{CN}$ was used as a solvent under aerial condition under blue LED light (Scheme 36a). ${ }^{52}\left(\mathrm{NH}_{4}\right)_{2} \mathrm{~S}_{2} \mathrm{O}_{8}$ was used as an oxidant. Although $\mathrm{N}$ aryl amino substituted coumarins underwent selenylation successfully, the authors failed to achieve any conversion to the product with $-\mathrm{NH}_{2}$ and $-\mathrm{NHMe}$ substituted coumarins under the reaction conditions. The authors also achieved dual selenylation selectively by reacting $N$-substituted 4-(phenylamino)- $2 \mathrm{H}$-chromen-2-one derivatives as substrates (Scheme $36 \mathrm{~b})$. The reaction showed excellent functional group tolerance for this reaction. The oxidant $\left(\mathrm{NH}_{4}\right)_{2} \mathrm{~S}_{2} \mathrm{O}_{8}$ formed sulfate radical anion intermediate under light which took part in single electron transfer process to initiate the reaction.

Recently Kumar \& co-workers have reported visible light mediated organoselenylation of indoles by diaryl selenides in acetone solvent under base and catalyst free conditions at room temperature in presence of oxygen (Scheme 37 ). ${ }^{53}$ The authors have used $26 \mathrm{~W}$ CFL bulb as light source and acetone as solvent. Several substituted indoles and electron rich arenes underwent selenylation by this protocol by producing 3-organoselenyl indoles in excellent yields under mild conditions. The authors have successfully applied this protocol for performing reaction with diarylditellurides towards the synthesis 3-tellenylindoles which was achieved for the first time under light. However the yields were lower in comparison to selenylation process. The authors also explored the scope of this reaction with diaryldisulfides and ammoniumthiocyanate to produce 3-sulfenyl indoles and 3-thiocyanoindoles respectively. The protocol was successfully applied for the synthesis of tubulin inhibitor. The reaction proceeded through the formation of radical cation intermediate $\mathbf{A}$ from indole by SET from indole to oxygen under visible light. As dichalcogenides are prone to radical attack, usual radical attack from $\mathbf{A}$ to dichalcogenides led to the formation of $\mathbf{B}$ which was converted into product via water exclusion by oxygen radical anion.

Kumaraswamy et al. proposed an atom economical $\mathrm{LiCl}$ promoted direct regioselective $\mathrm{C}\left(\mathrm{sp}^{2}\right)-\mathrm{H}$ selenation of indoles, imidazopyridines and electron-rich arenes under white LED irradiation without using any catalyst or sensitizer at room

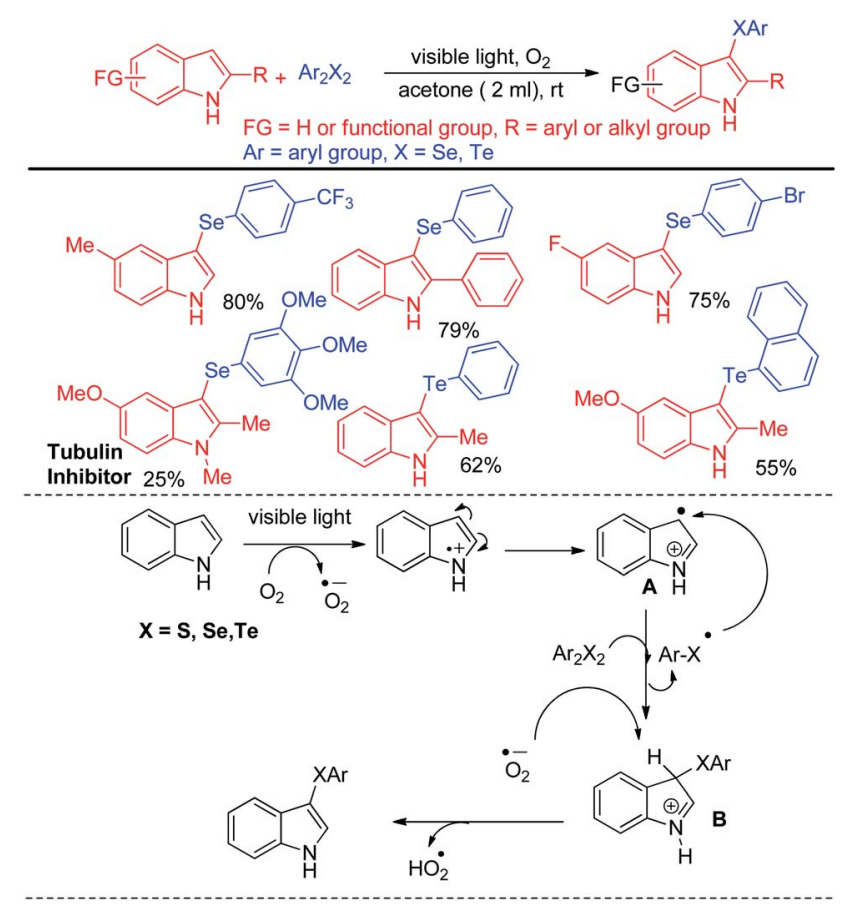

Scheme 37 Visible light mediated catalyst free 3-organochalcogenation of indoles. 


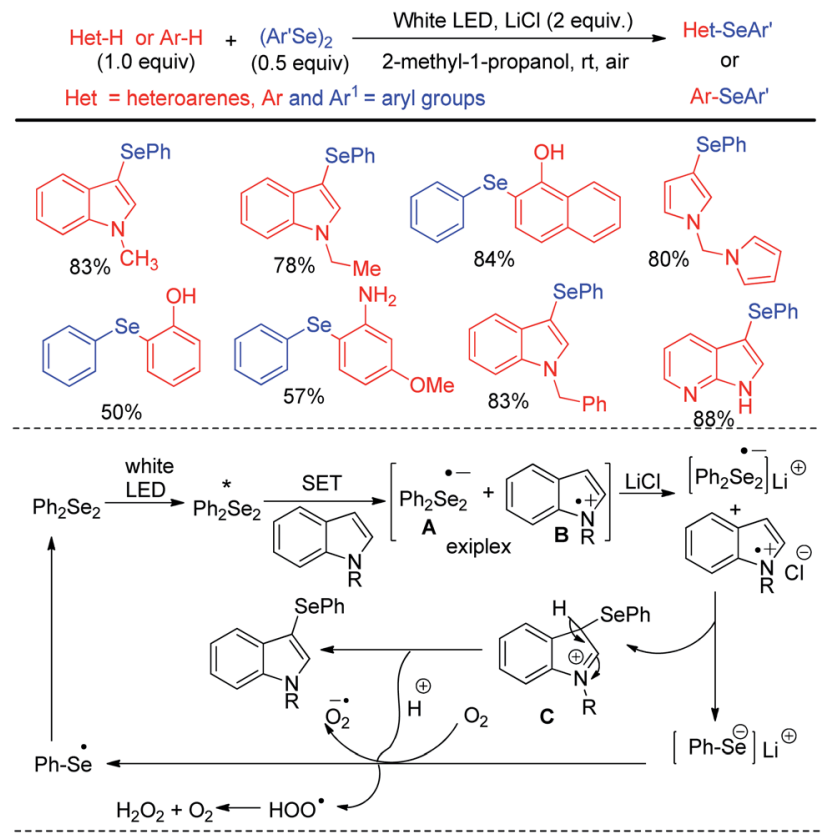

Scheme $38 \mathrm{LiCl}$ promoted $\mathrm{C}-\mathrm{H}$ selenylation of electron rich arenes and heteroarenes under white LED.

temperature under open air (Scheme 38$).{ }^{54}$ Using 0.5 equivalent of diselenides w.r.t. arenes or heteroarenes the authors have successfully performed selenylation in several $N$-protected or $\mathrm{NH}$-indoles, pyrroles and electron rich arenes in high yields. However the reaction did not produce any satisfactory result with taking with electron withdrawing $N$-protecting groups such as -boc, -tosyl etc. in indoles. The authors proposed radical mechanistic pathway for the reaction where diselenides were getting exited under white LED and electron transfer from indole leads to the formation of an exiplex bearing a radical anion (A) and a radical cation (B) intermediate. LiCl acted as stabilizer of the radical ion pair which indeed generated intermediate $\mathbf{C}$ that led to the formation of product by proton transfer towards oxygen radical anion. Heredia and Arguello et al. have developed visible light promoted regioselective synthesis of 3-selenylindoles from organic diselenides and

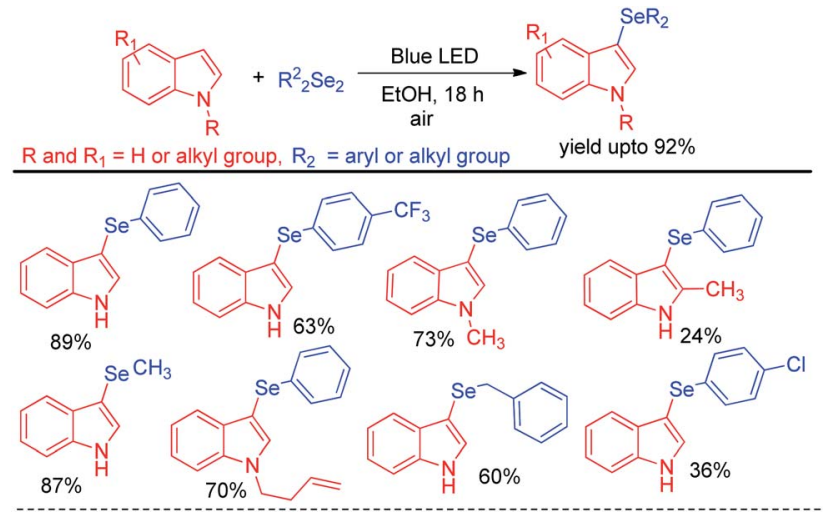

Scheme 39 Visible light mediated catalyst free $\mathrm{C}-\mathrm{H}$ selenation under air.

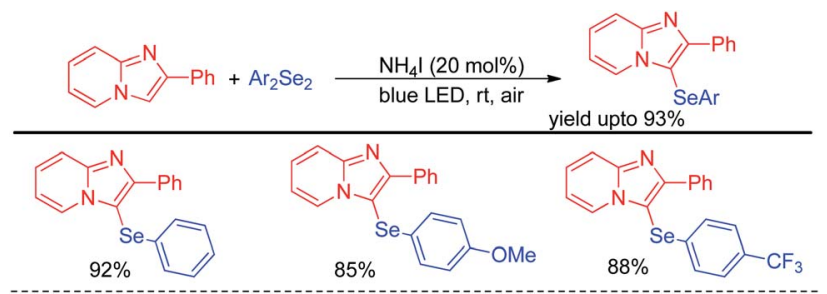

Scheme $40 \quad \mathrm{NH}_{4}$ l catalysed selenylation of 2-phenyl imidazopyridines under blue LED.

indole at room temperature in presence of air without under blue LED in absence of any photocatalyst (Scheme 39). ${ }^{55}$ The reactions were performed in green ethanol solvent. Several diaryl selenides have been also synthesized from electron-rich arenes under this reaction conditions in good to excellent yields. The reaction went through the common light mediated radical mechanistic path where oxygen played a crucial role by taking part in SET process through the formation of peroxo radical.

Yasuike et al. have reported $\mathrm{NH}_{4} \mathrm{I}$ catalyzed selenylation of 2phenyl imidazopyridines under blue LED at room temperature under aerial conditions (Scheme 40). ${ }^{56}$ The protocol was successfully applied for the synthesis of various 2-phenyl-3(arylselanyl)imidazo[1,2- $\alpha]$ pyridines in good to excellent yields.

Wang and coworkers have introduced visible light mediated photocatalyst free oxidative tandem cyclization of 2-alkynyl anilines with diselenides in presence of hydrogen peroxide for the synthesis of 3-selenoindole derivatives (Scheme 41). ${ }^{57}$ The reaction was initiated by hydroxyl radical, generated from hemolytic cleavage of $\mathrm{H}_{2} \mathrm{O}_{2}$ under blue LED. Single electron transfer from 2-alkynyl aniline generates intermediate $\mathbf{A}$ which via tandem cyclization formed intermediate $\mathbf{C}$ radical at the

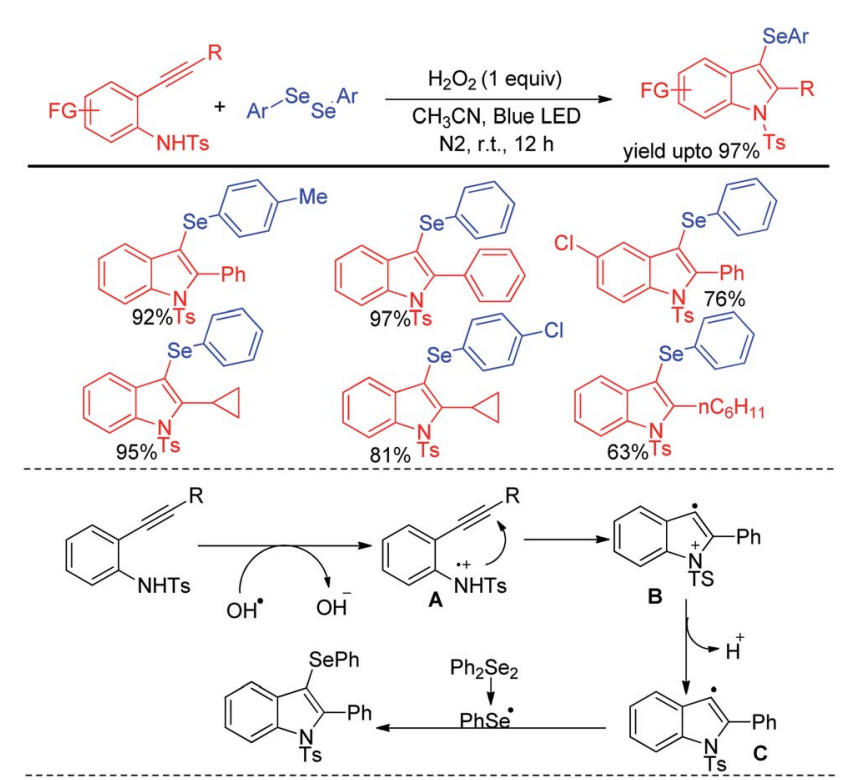

Scheme 41 Visible light mediated tandem cyclization of 2-alkynyl anilines in presence of $\mathrm{H}_{2} \mathrm{O}_{2}$. 
expense of proton. Reaction of $\mathbf{C}$ with diselenides produced the desired 3-selenoindoles. The reaction was however reported to be unsuccessful with ditellurides.

Apart from visible light mediated protocols Ogawa and coworkers in 2013 introduced a photoinduced reaction of organodiselenides with triaryl bismuthates for the formation of library of diaryl selenides under xenon lamp irradiation (Scheme 42). ${ }^{58}$ The reactions were performed in quartz test tube under room temperature.

\section{Under microwave irradiation}

Microwave assisted organic synthesis has emerged a powerful alternative of reactions under conventional heating due to its several advantages such as uniform heating, rapid reaction speed, absence of wanted side reaction, avoiding environmental heat loss and reduction of producing waste materials. Thus several microwave assisted protocols were developed for the synthesis of organochalcogenides. However the scope of transition metal catalyst free protocols for the synthesis of selenides and tellurides under microwave irradiation is still limited. Ranu et al. have reported the synthesis of unsymmetrical diaryl selenides and tellurides by reacting aryl diazonium fluoroborates with organodiselenides and tellurides respectively under microwave irradiation in short reaction time (Scheme 43). ${ }^{59}$

The zinc dust was used for the cleavage of diaryldichalcogenides which produced active nucleophile. The striking success of this protocol was its applicability of synthesizing large array of diaryl tellurides which was very less explored previously even by transition metal catalyzed protocols. A wide range of aryl diazonium fluoroborates having both electron donating (-OMe, $-\mathrm{OH},-\mathrm{OCF}_{3}$ etc.) and electron withdrawing groups (-COMe, $-\mathrm{COOMe},-\mathrm{CN},-\mathrm{F},-\mathrm{Br},-\mathrm{Cl},-\mathrm{COOH}$ etc.) were allowed to react with diphenyl diselenides/tellurides to provide the corresponding diaryl chalcogenides in high yields and high purity within a short reaction time by this protocol. The authors also explored the microwave assisted process for the synthesis of diaryl sulfides. The mechanism was proposed based on nucleophilic attack by $\mathrm{Zn}(\mathrm{SePh})_{2}$ on aryl diazonium fluoroborate and the product was obtained at the expense of $\mathrm{N}_{2}$. Braga and co-workers have proposed a novel idea of iodine catalyzed synthesis of unsymmetrical diarylselenides/ tellurides from boronic acids under microwave irradiation (100

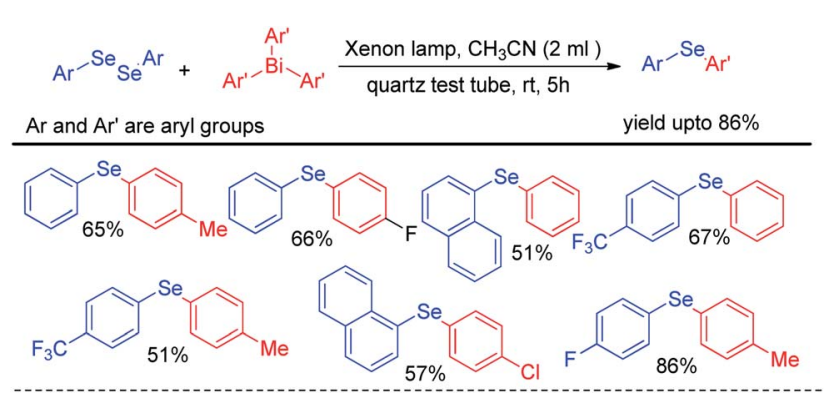

Scheme 42 Reaction of triaryl bismuthate with diselenides under xenon lamp irradiation.

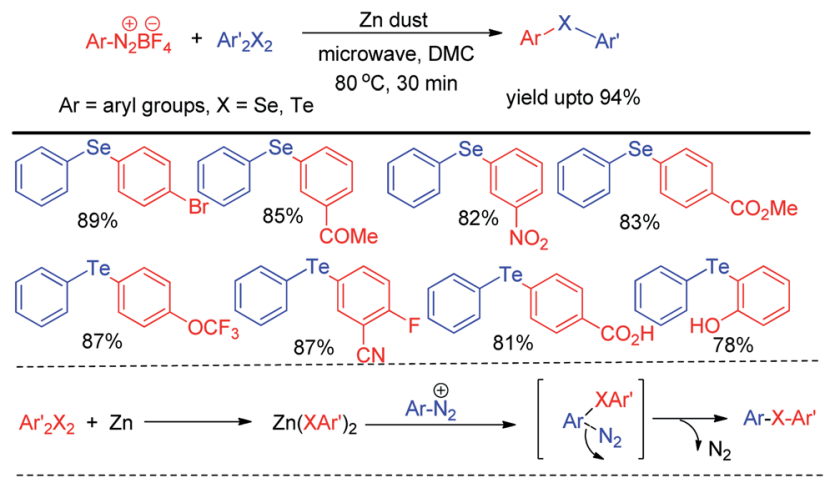

Scheme 43 Microwave assisted reaction of aryl diazonium fluoroborate with diselenides.

W) in absence of solvent. The coupling occurred in presence of 2 equiv. DMSO as oxidant (Scheme 44). ${ }^{60}$ A library of unsymmetrical diaryl/aryl-heteroaryl selenides and tellurides were synthesized in good to excellent yields with high functional group compatibility. First, diselenide reacts with Iodine to give RSeI as electrophilic intermediate. The possibility of involving radical mechanism was excluded by showing that TEMPO was ineffective in quenching the reaction. Thus the authors proposed an ionic mechanism where the desired product was obtained by nucleophilic attack from chalcogen center to the boron of boronic acid at the expense of $\mathrm{HI}$ which by the help of oxidant regenerated iodine.

\section{Under ball milling}

In recent years reactions under ball milling (intense mechanical grinding) have found considerable interest of synthetic chemists due to its greener applications in organic synthesis. ${ }^{\mathbf{6 1}}$ Performing reactions under solvent free conditions, room temperature and no general waste production made it a sustainable tool in synthetic chemistry. Thus ball milling was widely applied in different $\mathrm{C}-\mathrm{C}^{62}$ and $\mathrm{C}$-heteroatom ${ }^{63}$ bond

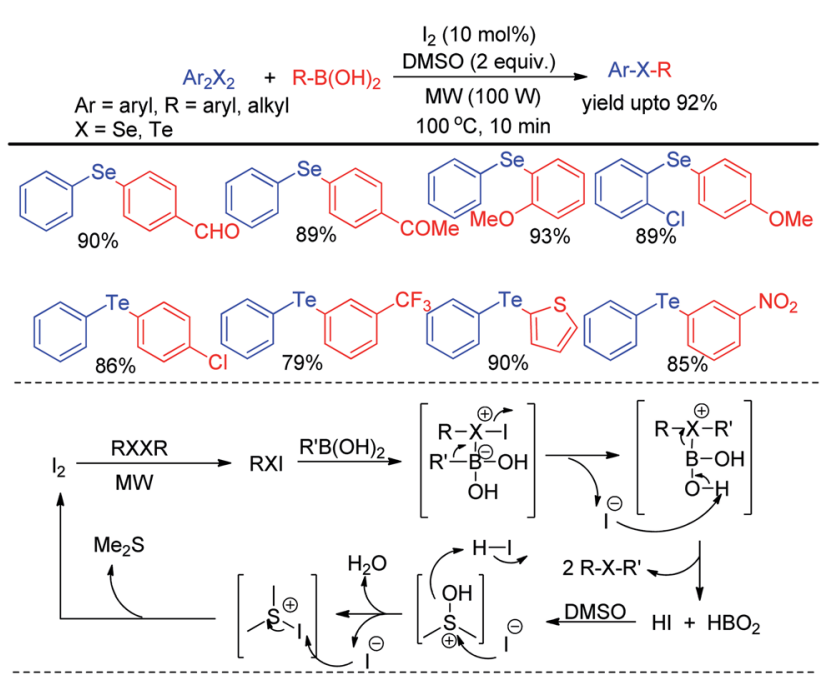

Scheme 44 Microwave assisted reaction of boronic acids with diselenides. 


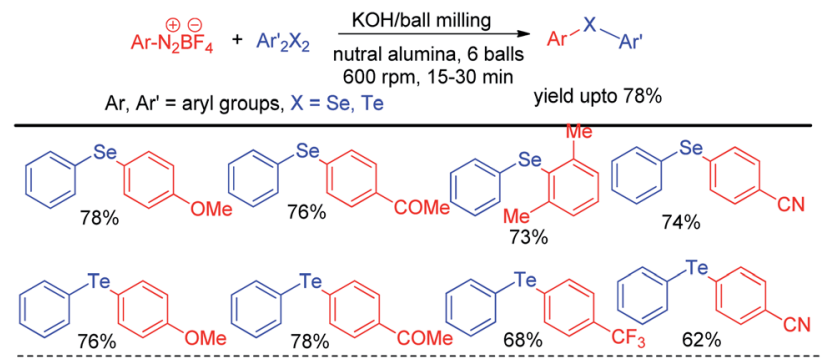

Scheme 45 Reaction of aryl diazonium fluoroborates with dichalcogenides under ball milling.

forming reactions in recent times for the synthesis of various important organic molecules for greener advancement w.r.t. their previously reported protocols. Ranu and coworkers have reported solvent free reaction of aryl diazonium fluoroborates with diaryldiselenides/tellurides for the synthesis of corresponding diaryl chalcogenides under ball milling in room temperature by using $\mathrm{KOH}$ as base (Scheme 45$)^{64}$ The main success of this protocol was it did not require formal work up or column chromatography. The product was obtained by simple elution of reaction mixture by ethanol or ethyl acetate followed by evaporation of solvent. Aryl diazonium fluoroborates with different electron donating and withdrawing groups in the aromatic ring were successfully converted into products in good moderate to good yields. The authors performed ball milling operation in inverted rotation directions, with an interval of $10 \mathrm{~min}$ and an interval break of 30 seconds. The authors also explored the scope of the reaction for the synthesis of diarylsulphides and dithiocarbamates. The authors have used neutral alumina and solid phase reaction medium under ball milling chamber.

The same group later explored the reaction with phenyl selenols with aryl diazonium fluoroborates under ball milling where they were able to find better yields for the synthesis of diaryl selenides in presence of milder base $\mathrm{K}_{2} \mathrm{CO}_{3}$ (Scheme 46$){ }^{65}$

\section{Under ultrasound}

Choudhury and co-workers have reported a simple and sustainable protocol for one-pot synthesis of 2-amino selenopyridines by performing multicomponent reaction of aldehydes, malononitrile and benzene selenol in reusable solvent polyethylene glycol (PEG-400) under ultrasonic irradiations (Scheme 47). ${ }^{66}$ A library of 2 -amino selenopyridines with

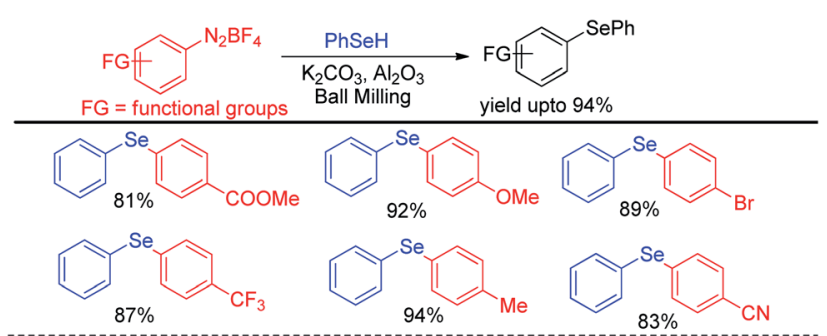

Scheme 46 Ball mill assisted reaction of phenyl selenols with diazonium salts under base free conditions.

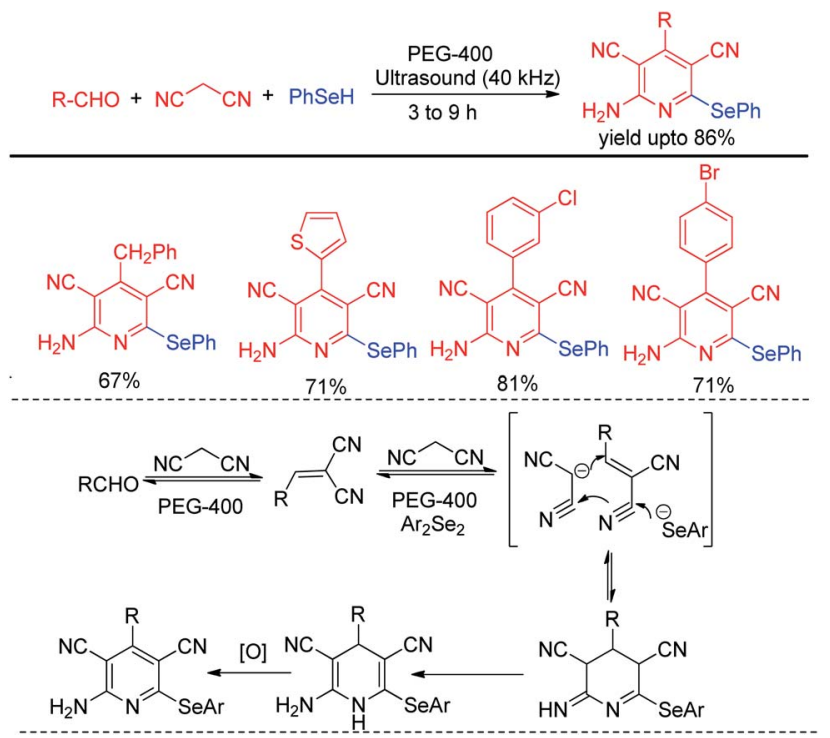

Scheme 47 One pot synthesis of 2-aminoselenopyridines via ultrasound assisted MCR.

different substituents have been synthesized under this reaction conditions in moderate to good yields. $o, o^{\prime}$-Disubstiuted aromatic aldehydes were also successful under the reaction conditions.

Perin et al. have developed ultrasound assisted synthesis of 2-organoselenyl-naphthalenes by reacting alkynoles with diaryldiselenides using oxone as oxidizing agent in water (Scheme 48) ${ }^{67}$ Electrophilic selenium species have been generated by the cleavage of Se-Se bond of diaryl selenides in the presence of oxone. Cyclization of alkynoles in presence of electrophilic selenium species led to the formation of product. Several substituted 2-organoselanyl-naphthalenes have been obtained in moderate to good yields in a short of time by this protocol. It was observed that the reaction requires 72 hours under conventional heating and thus the use of ultrasound for this reactions was time and energy efficient by large extent.

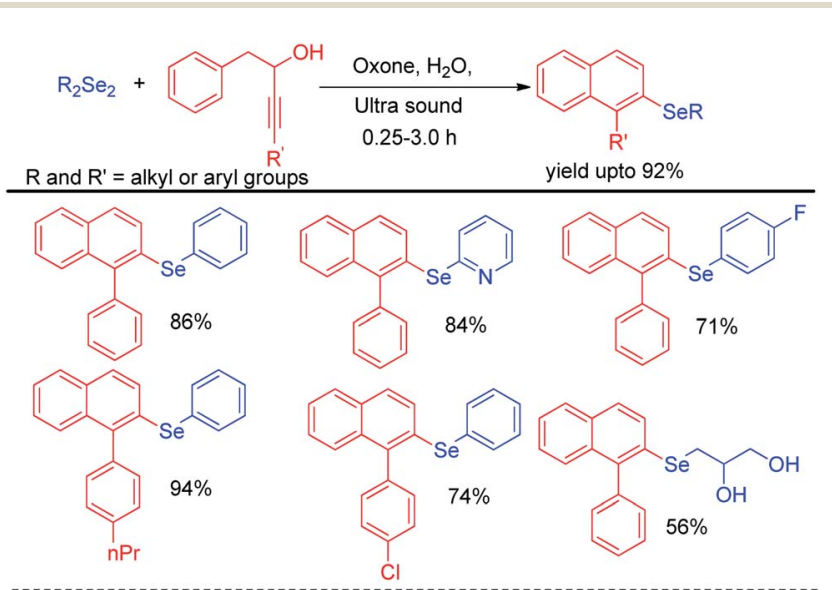

Scheme 48 Ultrasound assisted synthesis of 2-organoselenylnaphthalenes. 


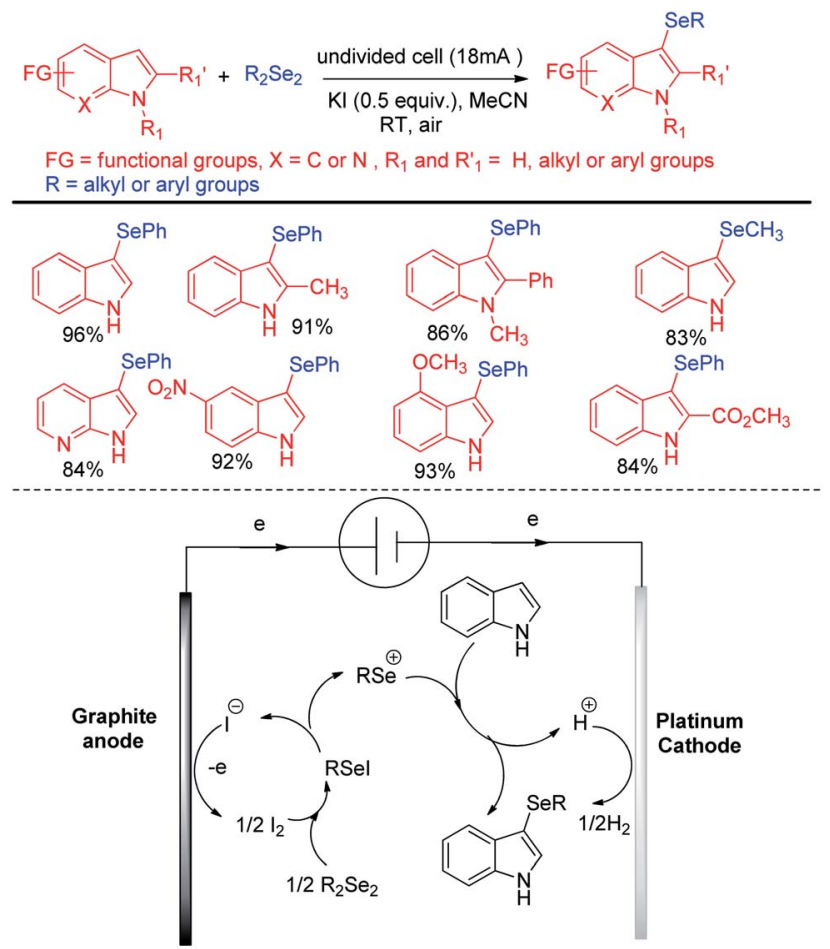

Scheme 49 lodide catalyzed electrochemical $\mathrm{C}-\mathrm{H}$ selenylation of indoles.

\section{Under electrochemical cell}

Electrochemistry has appeared as a sustainable alternative for organochalcogenide especially due to the current efficiency, high yield and control of the process.

Thus reactions can become economically and environmentally viable by using electrochemical procedures. ${ }^{68}$ Jian and Sun $e t$ $a l$. reported iodide ion catalyzed electrochemical selenylation of indoles and other heteroarenes in absence of any oxidizing agent (Scheme 49). ${ }^{69}$ The authors performed the reactions under undivided cell with graphite anode and platinum cathode under constant current of $18 \mathrm{~mA}$. The authors have proposed plausible path for this reaction bearing oxidation of iodide in anode and synthesis of active electrophile PhSeI. The product was obtained by usual deprotonation from heteroarenes where the liberated proton was reduced to hydrogen in cathode of the cell. Cao and Yu et al. reported an electrochemical cell based multicomponent reaction of 2-methyl pyridine, ketones and organodiselenides for the synthesis of diselenylated indolizines by using $\mathrm{K}_{2} \mathrm{CO}_{3}$ as base and $\mathrm{KI}$ as electrolyte under constant current of $10 \mathrm{~mA}$ (Scheme 50)..$^{70}$ The reaction required heating at $50{ }^{\circ} \mathrm{C}$. Large array of substituents were well tolerated in pyridine ring and aryl rings of diaryldiselenides. The in situ formed indolizidine underwent reaction with in presence of iodide under electrochemical cell to form the product.

\section{Future perspectives}

In spite of tremendous importance of transition metal catalyst free protocols for the synthesis of aryl and heteroaryl selenides

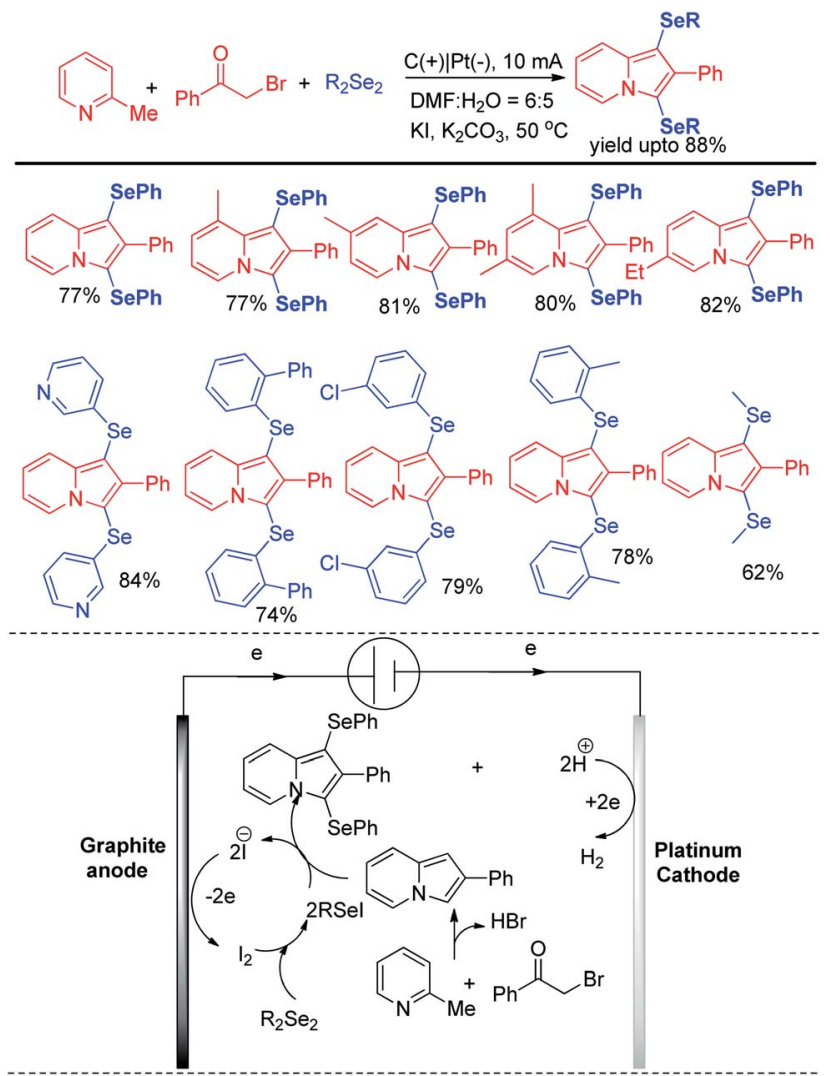

Scheme 50 Synthesis of diselenylindolizines by multicomponent reaction under electrochemical cell.

and tellurides challenges and opportunities remain: (1) C-Se bond formations in the electron deficient positions of arenes and heteroarenes. (3) Synthesis of aryl and heteroaryl tellurides is still less explored specially under metal free conditions. It is anticipated that these problems can be solved by developing proper organocatalytic systems in combination with photoredox catalysis.

\section{Conclusions}

Since last decade, a number of transition metal catalyst free protocols have been developed for $\mathrm{C}-\mathrm{Se}$ and $\mathrm{C}-\mathrm{Te}$ bond formations at the unsaturated carbon centres of aromatic rings and heterocycles. The advent of sustainable tools in performing C-Se \& C-Te cross-coupling under transition metal catalyst free conditions has resulted tremendous advantages in the field of sustainable organic synthesis. Apart from conventional methods, reactions under sustainable energy sources e.g. visible light photocatalysis, microwave irradiation, ball milling, ultrasound for the synthesis of aryl and heteroaryl selenides and tellurides have been highlighted in this review. Beside aryl selenides, different important Seneo-substituted heterocycles such as indole, imidazopyridine, quinolone, 1,3,4-oxazole, imidazothiazole, naphthofuran, imidazopyrimidine, pyrazoles, imidazole, thiophene, isocoumarin have been synthesized under transition metal free conditions and are discussed along 
with the mechanisms. More importantly these methodologies can be applied for the synthesis of aryl and heteroaryl selenide based medicinal and pharmaceutically important molecules and natural product by sustainable paths.

\section{Conflicts of interest}

There are no conflicts to declare.

\section{Acknowledgements}

Author acknowledge the financial support from Department of Science Technology \& Biotechnology, Govt. of West Bengal (WBDST), India with an award of "Gobesonai Bangla" Project funding to DK (grant no. 43(sanc)/ST/P/S\&T/15G-21/2018, dated 30/01/2019).

\section{Notes and references}

1 (a) Handbook of Chalcogen Chemistry: New Perspectives in Sulfur, Selenium and Tellurium, ed. F. A. Devillanova and W.-W. du Mont, RSC Publishing, Cambridge, 2nd edn, 2013, ISBN: 978-1-84973-624-4; (b) PATAI's Chemistry of Functional Groups: The Chemistry of Organic Selenium and Tellurium Compounds, ed. Z. Rappoport, Wiley, 2013, ISBN: 978-1-118-33693-9.

2 K. Selvakumar and H. B. Singh, Chem. Sci., 2018, 9, 7027.

3 (a) S. Patai and Z. Rappoport, in The Chemistry of Organic Selenium and Tellurium Compounds, John Wiley and Sons, New York, NY, 1987, vol. 2; (b) J. Hellberg, T. Remonen, M. Johansson, O. Inganas, M. Theander, L. Engman and P. Eriksson, Synth. Met., 1997, 84, 251; (c) G. Evano, N. Blanchard and M. Toumi, Chem. Rev., 2008, 108, 3054; (d) T. Wirth, Organoselenium Chemistry: Synthesis and Reactions, Wiley-VCH, Weinheim, Germany, 2012, pp. 1-65; (e) S. T. Manjare, Y. Kim and D. G. Churchill, Acc. Chem. Res., 2014, 47, 2985; (f) D. S. Rampon, F. S. Rodembusch, J. M. F. M. Schneider, L. H. Bechto, P. F. B. Gonçalves, A. A. Merlo and P. H. Schneider, J. Mater. Chem., 2010, 20, 715.

4 (a) M. Besev and L. Engman, Org. Lett., 2002, 4, 3023; (b) B. Berlin, C. Ericsson and L. Engman, J. Org. Chem., 2003, 68, 8386; (c) D. M. Freudendahl, S. Santoro, S. A. Shahzad, C. Santi and T. Wirth, Angew. Chem., Int. Ed., 2009, 48, 8409; (d) P. Srivastava and L. Engman, Tetrahedron Lett., 2010, 51, 1149.

5 (a) Applications of Chalcogenides: S, Se, and Te, ed. G. K. Ahluwalia, Springer, 2017, ISBN: 978-3-319-41190-3; (b) M. Chhowalla, Z. Liu and H. Zhang, Chem. Soc. Rev., 2015, 44, 2584-2586, editorial for the themed collection: twodimensional transition metal dichalcogenide (TMD) nanosheets.

6 (a) Selenium and Tellurium Reagents in Chemistry and Material Science, ed. R. S. Laitinen and R. Oilunkaniemi, De Gruyter, 2019, ISBN: 978-3-11-052794-0; (b) E. J. Lenardão, C. Santi and L. Sancineto, New Frontiers in Organoselenium Compounds, Springer, 2018, ISBN: 978-3-319-92405-2.
7 Organoselenium Compounds in Biology and Medicine: Synthesis, Biological and Therapeutic Treatments, ed. V. K. Jain and K. I. Priyadarsini, RSC Publishing, Cambridge, 2017, ISBN: 978-1-78801-029-0.

8 (a) B. K. Sarma and G. Mugesh, Org. Biomol. Chem., 2008, 6, 965; (b) G. Mugesh and H. B. Singh, Chem. Soc. Rev., 2000, 29, 347; (c) J. A. Woods, J. A. Hadfield, A. T. McGown and B. W. Fox, Bioorg. Med. Chem., 1993, 1, 333; (d) L. Engman, D. Stern, H. Frisell, K. Vessman, M. Berglund, B. Ek and C.-M. Andersson, Bioorg. Med. Chem., 1995, 3, 1255; (e) V. Nascimento, E. E. Alberto, D. W. Tondo, D. Dambrowski, M. R. Detty, F. Nome and A. L. Braga, J. Am. Chem. Soc., 2012, 134, 138; (f) D. Plano, D. N. Karelia, M. K. Pandey, J. E. Spallholz, S. Amin and A. K. Sharma, J. Med. Chem., 2016, 59, 1946.

9 (a) Y. Pang, B. An, L. Lou, J. Zhang, J. Yan, L. Huang, X. Li and S. Yin, J. Med. Chem., 2017, 60, 7300; (b) L. Sancineto, A. Mariotti, L. Bagnoli, F. Marini, J. Desantis, N. Iraci, C. Santi, C. Pannecouque and O. Tabarrini, J. Med. Chem., 2015, 58, 9601; (c) D. de Souza, D. O. C. Mariano, F. Nedel, E. Schultze, V. F. Campos, F. Seixas, R. S. da Silva, T. S. Munchen, V. Ilha, L. Dornelles, A. L. Braga, J. B. T. Rocha, T. Collares and O. E. D. Rodrigues, J. Med. Chem., 2015, 58, 3329.

10 (a) Z. Wang, Y. Wang, W. Li, F. Mao, Y. Sun, L. Huang and X. Li, ACS Chem. Neurosci., 2014, 5, 952; (b) Q. Guan, C. Han, D. Zuo, M. Zhai, Z. Li, Q. Zhang, Y. Zhai, X. Jiang, K. Bao, Y. Wu and W. Zhang, Eur. J. Med. Chem., 2014, 87, 306.

11 (a) Z. Wen, X. Li, D. Zuo, B. Lang, Y. Wu, M. Jiang, H. Ma, K. Bao, Y. Wu and W. Zhang, Sci. Rep., 2016, 6, 23986; (b) S. Kumar, N. Sharma, I. K. Maurya, A. K. K. Bhasin, N. Wangoo, P. Brandao, V. Felix, K. K. Bhasin and R. K. Sharma, Eur. J. Med. Chem., 2016, 123, 916.

12 (a) T. V. Sravanthi and S. L. Manju, Eur. J. Pharm. Sci., 2016, 91, 1; (b) N. K. Kaushik, N. Kaushik, P. Attri, N. Kumar, C. H. Kim, A. K. Verma and E. H. Choi, Molecules, 2013, 18, 6620; (c) Y. Abe, H. Kayakiri, S. Satoh, T. Inoue, Y. Sawada, N. Inamura, M. Asano, I. Aramori, C. Hatori, H. Sawai, T. Oku and H. Tanaka, J. Med. Chem., 1998, 41, 4587.

13 I. P. Beletskaya and V. P. Ananikov, Chem. Rev., 2011, 111, 1596.

14 G. Perin, D. Alves, R. G. Jacob, A. M. Barcellos, L. K. Soares and E. J. Lenardao, ChemistrySelect, 2016, 2, 205.

15 S. Ahammed, D. Kundu, N. Mukherjee and B. C. Ranu, Curr. Microwave Chem., 2017, 4, 25.

16 A. Ivanova and P. Arsenyan, Coord. Chem. Rev., 2018, 370, 55. 17 C. S. Freitas, A. M. Barcellos, V. G. Recordi, J. M. Pena, G. Perin, R. G. Jacob, E. J. Lenardao and D. Alves, Green Chem., 2011, 13, 2931.

18 E. G. Zimmermann, S. Thurow, C. S. Freitas, S. R. Mendas, G. Perin, D. Alves and E. J. Lenardao, Molecules, 2013, 18, 4081.

19 J. Liu, P. Li, W. Chen and L. Wang, Chem. Commun., 2012, 48, 10052. 
20 C. D. Prasad, S. J. Balkrishna, A. Kumar, B. S. Bhakuni, K. Shrimali, S. Biswas and S. Kumar, J. Org. Chem., 2013, $78(4), 1434$.

21 S. Thurow, R. Webber, G. Perin, E. J. Lenarda and D. Alves, Tetrahedron Lett., 2013, 54, 3215.

22 R. A. Balaguez, V. G. Ricordi, C. S. Freitas, G. Perin, R. F. Schumacher and D. Alves, Tetrahedron Lett., 2014, 55, 1057.

23 S. Kumar, N. Sharma, I. K. Maurya, A. K. Bhasin, N. Wangoo, P. Brandao, V. Felix, K. K. Bhasin and R. K. Sharma, Eur. J. Med. Chem., 2016, 123, 916.

24 S. Thurow, F. Penteado, G. Perin, R. G. Jacob, D. Alves and E. J. Lenardão, Green Chem., 2014, 16, 3854.

25 L. Savegnago, A. I. Vieira, N. Seus, B. S. Goldani, M. R. Castro, E. J. Lenardao and D. Alves, Tetrahedron Lett., 2013, 54, 40.

26 J. Rafique, S. Saba, A. R. Rosario, G. Zeni and A. L. Braga, RSC Adv., 2014, 4, 51648.

27 S. Jana, A. Chakraborty, S. Mondal and A. Hajra, RSC Adv., 2015, 5, 77534.

28 J. Ratique, S. Saba, A. R. Rosario and A. L. Braga, Chem.-Eur. J., 2016, 33, 11854.

29 P. Maity, S. Ahammed, R. N. Manna and B. C. Ranu, Org. Chem. Front., 2017, 4, 69.

30 T. Taniguchi, A. Murata, M. Takeda, T. Mizuno, A. Nomoto and A. Ogawa, Eur. J. Org. Chem., 2017, 4928.

31 Y. Guan and S. D. Townsend, Org. Lett., 2017, 19, 5252.

32 G. Kiribya, S. Samanta, M. Singsardar, S. Jana and A. Hajra, Eur. J. Org. Chem., 2017, 3055.

33 L. Bettanin, S. Saba, C. V. Doerner, M. S. Franco, M. Godoi, J. Rafique and A. L. Braga, Tetrahedron Lett., 2018, 74, 3971.

34 T. Ghosh, N. Mukherjee and B. C. Ranu, ACS Omega, 2018, 3, 17540.

35 S. K. Bhunia, P. Das and R. Jana, Org. Biomol. Chem., 2018, 16, 9243.

36 R. An, L. Liao, X. Liu, S. Song and X. Zhao, Org. Chem. Front., $2018,5,3557$.

37 A. Dey and A. Hajra, J. Org. Chem., 2019, 84, 14904.

38 Y. Fang, J. Wang, Y. Liu and J. Yan, J. Organomet. Chem., 2019, 33, e4921.

39 L. Xing, Y. Zhang, B. Li and Y. Du, Org. Lett., 2019, 10, 3620. 40 Q. Glenadel, E. Ismalai and T. Billard, Org. Lett., 2018, 20, 56.

41 C. Ding, Y. Zu, Q. Yu, Z. Xie, Y. Zhou, J. Zhou, G. Liang and Z. Song, ChemCatChem, 2018, 10, 5397.

42 D.-Y. Wang, X. Wen, C.-D. Xiong, J. N. Zhao, C.-Y. Ding, Q. Meng, H. Zhou, C. Wang, M. Uchiyama, X.-J. Lu and A. Zhang, iScience, 2019, 15, 307.

43 J.-N. Zhao, M. Kayumov, D.-Y. Wang and A. Zhang, Org. Lett., 2019, 21, 7303.

44 T. Guo, X.-N. Wei, Y. Liu, P.-K. Zhang and Y.-H. Zhao, Org. Chem. Front., 2019, 6, 1414.

45 N. Jiang, Y. Fang, Y. Fang, S.-Y. Wang and S.-J. Ji, Org. Chem. Front., 2019, 6, 654.

46 Y.-C. Shieh, K. Du, R. S. Basha, Y.-J. Xue, B.-H. Shih, L. Li and C.-F. Lee, J. Org. Chem., 2019, 84, 6223.
47 M. C. D. F. Xavier, E. M. A. Sandagorda, J. S. S. Neto, R. F. Schumacher and M. S. Silva, RSC Adv., 2020, 10, 13975. 48 A. L. Belladona, R. Cervo, D. Alves, T. Barcellos, R. Cargnelutti and R. F. Schumacher, Tetrahedron Lett., 2020, 61, 152035.

49 D. Kundu, S. Ahammed and B. C. Ranu, Org. Lett., 2014, 16, 1814.

50 Q.-B. Zhang, Y.-L. Ban, P.-F. Yuan, S.-J. Peng, J.-G. Fang, L.-Z. Wu and Q. Liu, Green Chem., 2017, 19, 5559.

51 S. Saba, J. Rafique, M. S. Franco, A. R. Schneider, L. Espindola, D. O. Silva and A. L. Braga, Org. Biomol. Chem., 2018, 16, 880.

52 D. Yang, G. Li, C. Xing, W. Cui, K. Li and W. Wei, Org. Chem. Front., 2018, 5, 2974.

53 V. Rathore and S. Kumar, Green Chem., 2019, 21, 2670.

54 G. Kumaraswamy, V. Ramesh, M. Gangadhar and S. Vijaykumar, Asian J. Org. Chem., 2018, 7, 1689.

55 I. D. Lemir, W. D. Castro-Goddy, A. A. Heredia, L. C. Schmidt and J. E. Arguello, RSC Adv., 2019, 9, 22685.

56 Y. Murata, K. Kanasaki, K. Kondo, N. Kakusawa, M. Matsumura and S. Yasuike, Heterocycles, 2019, 99, 596.

57 Q. Shi, P. Li, Y. Zhang and L. Wang, Org. Chem. Front., 2017, 4, 1322.

58 Y. Kobiki, S. Kawaguchi, I. Ohe and A. Ogawa, Beilstein J. Org. Chem., 2013, 9, 1141.

59 D. Kundu, S. Ahammed and B. C. Ranu, Green Chem., 2012, 14, 2024.

60 S. Saba, J. Rafique and A. L. Braga, Adv. Synth. Catal., 2015, 357, 1554.

61 (a) A. Stolle, T. Szuppa, S. E. S. Leonhardt and B. Ondruschka, Chem. Soc. Rev., 2011, 40, 2317; (b) G.-W. Wang, Chem. Soc. Rev., 2013, 42, 7668.

62 (a) R. Schimdt, R. Throwirth, T. Szuppa, A. Stolle, B. Ondruschka and H. Hopf, Chem.-Eur. J., 2011, 17, 8129; (b) R. Throwirth, A. Stolle and B. Ondruschka, Green Chem., 2010, 12, 985.

63 (a) J. G. Hernande and E. J. Juaristi, J. Org. Chem., 2010, 75, 710; (b) J. Bonnamour, T.-X. Metro, J. Martinez and F. Lamarty, Green Chem., 2013, 15, 1116.

64 N. Mukherjee, T. Chatterjee and B. C. Ranu, J. Org. Chem., 2013, 78, 11110.

65 N. Mukherjee, T. Chatterjee and B. C. Ranu, Arkivoc, 2016, 2, 53.

66 M. N. Khan, S. Karamthulla, L. H. Choudhury and M. S. H. Faizi, RSC Adv., 2015, 5, 22168.

67 G. Perin, D. R. Araujo, P. C. Nobre, E. J. Lenardao, R. G. Jacob, M. S. Silva and J. A. Roehrs, PeerJ, 2018, 6, e4706. 68 P. B. R. Neto, S. O. Santana, G. Levitre, D. Galdino, J. L. Oliveira, R. T. Ribeiro, M. S. E. B. Barros and L. W. M. Navarro, Green Chem., 2016, 18, 657.

69 X. Zhang, C. Wang, H. Jiang and L. Sun, Chem. Commun., 2018, 54, 8781.

70 J. Li, X. Liu, J. Deng, Y. Huang, Z. Pan, Y. Yu and H. Cao, Chem. Commun., 2020, 56, 735. 